\title{
Estrutura econômica do estado do Piauí nos anos de 2010 e 2015: uma contribuição a partir da abordagem insumo-produto*
}

\author{
Piaui State Economic Structure in 2010 and 2015: A Contribution from the \\ Input-Output Approach
}

Joelson Oliveira Santos, Rafael de Sousa Araújo e Fabrício Pitombo Leite**

\begin{abstract}
Resumo: O trabalho objetiva traçar prognósticos acerca da estrutura produtiva piauiense nos anos de 2010 e 2015 por meio de diferentes indicadores relacionados à análise insumo-produto, de forma que, a partir dos resultados encontrados, possam ser oferecidas informações que sirvam de subsídios para as políticas de planejamento do estado do Piauí. Para tanto, tomando por base a matriz insumo-produto nacional e uma combinação de quocientes locacionais simples e regionalização das matrizes através do método RAS, estima-se um esquema insumo-produto estadual contemplando 40 atividades, a partir do qual, identifica-se o perfil tecnológico do sistema econômico estadual, através de indicadores estruturais de encadeamento. Os resultados denotam que a economia piauiense apresenta problemas no que tange à complementaridade entre suas atividades produtivas, relativamente pouco encadeadas quando comparadas à dimensão nacional. Ademais, os resultados significativamente díspares do nacional implicam que os efeitos de transbordamento do crescimento do país para o Piauí, pouco afetariam a produção piauiense.
\end{abstract}

Palavras-chave: Matriz insumo-produto; Estrutura produtiva; Piauí

\begin{abstract}
This paper aims to draw predictions about the productive structure of Piauí in the years 2010 and 2015 through different indicators related to the input-output analysis, so that, based on the results found, information can be provided to support planning policies in the state of Piauí. To this end, based on the national input-output matrix and on a combination of simple location quotients and matrix regionalization using the RAS method, it's estimated a state input-output scheme contemplating 40 activities, from which the technological profile of the state economic system is identified through structural indicators of linkages. The results show that the economy of Piauí presents problems in terms of the complementarity between its productive activities, relatively poorly linked when compared to the national dimension. In addition, the significantly

\footnotetext{
* Submissão: 12/11/2019 | Aprovação: 01/08/2020 | DOI: 10.5380/re.v42i78.70160

** Respectivamente: (1) Doutorando no Programa de Pós-Graduação em Economia da Universidade Federal do Rio Grande do Sul (PPGE-UFRGS), Brasil |E-mail: joelsonsantosrdp@ hotmail.com | ORCID: 0000-00019689-9505 | (2) Doutorando no Programa de Pós-Graduação em Economia da Universidade Federal de Pernambuco (PIMES-UFPE), Brasil | E-mail: rafaelaraujo05@ hotmail.com | ORCID: 0000-0001-6680-8019 | (3) Professor Adjunto da Universidade Federal da Bahia (UFBA), Brasil | E-mail: fabricio.leite@ufba.br | ORCID: 0000-0003-4333-509X
} 
different results from the national imply that the spillover effects of the country's growth to Piauí would have little effect on piauiense production.

Keywords: Input-output matrix; Production structure; Piauí

JEL: C67; R58 


\section{Introdução}

A Matriz de Insumo-Produto (MIP) - também conhecida como análise interindustrial $^{1}$ - é um método desenvolvido por Leontief capaz de revelar a interdependência entre os diferentes ramos da economia, analisando aspectos estruturais de produção, suas trocas e tendências ao longo do tempo, sem necessidade de recorrer a softwares sofisticados (Schuschny, 2005). A importância dessa técnica se dá, de modo geral, pelo fato de que as mensurações de contas nacionais não conseguem demonstrar essa interdependência multissetorial da economia. Segundo Guilhoto (2014, p. 11), ela possibilita "uma visão única e compreensiva de como a economia funciona". Leontief (1986) vê as relações entre os agentes econômicos como uma cadeia de interações bem definidas. Em suas palavras,

The effect of an event at any one point is transmitted to the rest of the economy step by step via the chain of transactions that links the whole system together. A table of ratios for the entire economy gives us, in as much detail as we require, a quantitatively determined picture of the internal structure of the system ${ }^{2}$ (Leontief, 1986, p. 14).

A composição da matriz se resume basicamente entre a demanda intermediária, a demanda total final e o valor agregado pelos setores. A mensuração dessas matrizes, na prática, é realizada levando-se em conta os preços relativos entre as diversas atividades econômicas.

Com o passar do tempo, houve uma grande evolução sobre a teoria e prática do método de insumo-produto que tem possibilitado diversas contribuições técnicas à análise econômica. Entre essas contribuições, tem-se: definição de setores-chave (promotores de crescimento e desenvolvimento econômico), acompanhamento das mudanças temporais no nível de produção setorial e na demanda agregada, identificação de clusters e complexos produtivos, entre outros (Guilhoto, 2014).

De posse de matrizes nacionais, a abordagem pode ser estendida para regiões, estados, municípios, etc., mediante a adoção de ajustes e opções metodológicas ${ }^{3}$. Nesse sentido, no Brasil, destacam-se o trabalho realizado pelo

\footnotetext{
${ }^{1}$ Vide Miller e Blair (2009).

${ }^{2} \mathrm{O}$ efeito de um evento em qualquer ponto é transmitido ao resto da economia, passo a passo, através da cadeia de transações que liga todo o sistema. Uma tabela de proporções para toda a economia nos dá, com tantos detalhes quanto exigimos, uma imagem quantitativamente determinada da estrutura interna do sistema (Tradução nossa).

${ }^{3}$ Vide Miller e Blair (2009).
} 
Núcleo de Economia Regional e Urbana (Nereus) da Universidade de São Paulo, cuja metodologia pode ser encontrada em Guilhoto et al. (2010) e mais recentemente em Haddad, Gonçalves Júnior e Nascimento (2018), e o método desenvolvido no Grupo de Estudos de Relações Intersetoriais (Geri) da Universidade Federal da Bahia, sintetizado nos trabalhos de Leite e Pereira (2010), Ribeiro e Leite (2012) e Ribeiro et al. (2013). Em um contexto específico para a região Nordeste, pode-se mencionar os trabalhos empreendidos por Leite (2016) e Santos et al. (2020), que consistiram na estimação de um esquema insumo-produto para o estado do Rio Grande do Norte, estudos realizados para o estado da Bahia utilizando o arcabouço da análise insumo-produto (Leite; Pereira, 2010; Perobelli et al., 2015; Ribeiro; Leite, 2014) e Ribeiro e Leite (2012) através do estudo da estrutura econômica do estado de Sergipe.

Apesar dos esforços desses autores, não há um estudo particular para o Piauí baseado nesse arcabouço. Dessa forma, este trabalho procura suprir essa lacuna ao trazer prognósticos sobre a estrutura produtiva piauiense, através de diferentes indicadores relacionados à análise insumo-produto. Sendo assim, diante da constatação de que o estado ainda carece de um conjunto de informações que norteiem e potencializem o seu processo de desenvolvimento, o presente trabalho pode servir de suporte ao estabelecimento de critérios para políticas que atinjam seus setores mais dinâmicos e, consequentemente, gerem emprego e desenvolvimento local, bem como sirva de elementos para tomada de decisão do segmento empresarial.

De modo a alcançar o objetivo proposto, tomando por base a matriz insumoproduto nacional e uma combinação de quocientes locacionais simples e regionalização das matrizes através da adoção do método RAS de extrapolação de matrizes biproporcionais, estima-se um esquema insumo-produto para o estado contemplando 40 atividades nos anos de 2010 e 2015.

O trabalho está estruturado em quatro partes, além desta introdução. A próxima seção apresenta alguns dados conjunturais da economia piauiense. A terceira detalha a metodologia utilizada para estimação do esquema insumo-produto estadual. A quarta seção, por sua vez, apresenta os resultados encontrados para os encadeamentos produtivos entre as atividades e os setores-chave para o Piauí nos anos analisados. Por fim, a quinta seção destina-se às considerações finais. 


\section{Conjuntura econômica e representação piauiense na produção nacional}

Como na grande parte das diversas regiões, a economia piauiense tem na atividade de serviços sua maior contribuinte para o PIB local. Todavia, quando comparado à economia nacional, seu setor de destaque é a agricultura (IBGE, 2018b). Levando isso em consideração, propõe-se aqui apresentar alguns indicadores relacionados ao PIB por dimensão territorial, com intuito de fazer um comparativo participativo.

A Tabela 1 apresenta o PIB a preços de mercado corrente do Brasil, do Nordeste e do Piauí. Percebe-se que o estado piauiense contribui muito pouco para o PIB nacional. É uma economia que pouco produz. Isso está atrelado ao fato de essa economia dedicar-se à produção de bens com baixo valor agregado, contribuindo, assim, com menos de $1 \%$ ao PIB nacional, e menos de $5 \%$ ao regional.

Tabela 1 - PIB a preços de mercado corrente - R\$ (mil)

\begin{tabular}{l|rrrrrrrrr}
\hline \multirow{2}{*}{ Região } & \multicolumn{10}{|c}{ Ano } \\
\cline { 2 - 10 } & $\mathbf{2 0 0 0}$ & $\begin{array}{c}\text { Part. } \\
(\boldsymbol{\%})\end{array}$ & $\mathbf{2 0 0 5}$ & $\begin{array}{c}\text { Part. } \\
(\boldsymbol{\%})\end{array}$ & $\mathbf{2 0 1 0}$ & $\begin{array}{r}\text { Part. } \\
(\boldsymbol{\%})\end{array}$ & $\mathbf{2 0 1 5}$ & $\begin{array}{r}\text { Part. } \\
(\boldsymbol{\%})\end{array}$ \\
\hline Brasil & 1.179 .482 .000 & 100 & 2.147 .239 .000 & 100 & 3.770 .084 .872 & 100 & 5.995 .787 .000 & 100 \\
Nordeste & 146.827 .013 & 12,45 & 280.545 .017 & 13,07 & 507.501 .607 & 13,5 & 848.579 .383 & 14,2 \\
Piauí (BR) & 6.062 .726 & 0,51 & 11.129 .200 & 0,52 & 22.060 .161 & 0,57 & 39.149 .686 & 0,65 \\
Piauí (NE) & 6.062 .726 & 4,13 & 11.129 .200 & 3,97 & 22.060 .161 & 4,35 & 39.149 .686 & 4,61 \\
\hline
\end{tabular}

Fonte: Instituto Brasileiro de Geografia e Estatística (IBGE). Elaboração própria.

Conforme mencionado previamente, a produção de bens e serviços do estado concentra-se no setor de serviços, média de 77,76\% de participação no PIB estadual entre os anos de 2010 e 2015, seguida pela indústria, média de 14,94\%, e agropecuária, em média 7,30\% (ver Tabela 2). No tocante ao Valor Adicionado Bruto (VAB), o Piauí apresentava, em 2010, um VAB total de, aproximadamente, 19,7 bilhões de reais, correspondentes a 0,60\% do VAB nacional (IBGE, 2018b). Em relação ao Nordeste, no mesmo ano, o estado representava 4,29\% do VAB da região. Em 2015, tais participações estaduais elevaram-se para 0,68\% do VAB nacional e $4,69 \%$ do $\mathrm{VAB}$ regional. 
Tabela 2 - Participações das atividades no Valor Adicionado Bruto - Brasil e Piauí (2010 e 2015)

\begin{tabular}{|c|c|c|c|c|}
\hline \multirow{3}{*}{ Atividades Econômicas } & \multicolumn{4}{|c|}{$\begin{array}{l}\text { Participação no Valor } \\
\text { Adicionado Bruto }(\%)\end{array}$} \\
\hline & \multicolumn{2}{|c|}{ Brasil } & \multicolumn{2}{|c|}{ Piauí } \\
\hline & 2010 & 2015 & 2010 & 2015 \\
\hline Agropecuária & 4,84 & 5,02 & 6,00 & 7,80 \\
\hline $\begin{array}{l}\text { Agricultura, inclusive apoio à agricultura e a pós- } \\
\text { colheita }\end{array}$ & 3,03 & 3,16 & 3,41 & 5,27 \\
\hline Pecuária, inclusive apoio à Pecuária & 1,36 & 1,39 & 1,90 & 1,72 \\
\hline Produção florestal, pesca e aquicultura & 0,45 & 0,47 & 0,68 & 0,81 \\
\hline Indústria & 27,38 & 22,52 & 16,28 & 13,55 \\
\hline Indústrias extrativas & 3,33 & 2,15 & 0,72 & 0,12 \\
\hline Indústrias de transformação & 14,97 & 12,24 & 5,20 & 4,24 \\
\hline $\begin{array}{l}\text { Eletricidade e gás, água, esgoto, atividades de gestão } \\
\text { de resíduos e descontaminação }\end{array}$ & 2,81 & 2,39 & 1,98 & 0,92 \\
\hline Construção & 6,27 & 5,74 & 8,38 & 8,28 \\
\hline Serviços & 67,78 & 72,46 & 77,72 & 78,65 \\
\hline $\begin{array}{l}\text { Comércio e reparação de veículos automotores e } \\
\text { motocicletas }\end{array}$ & 12,60 & 13,30 & 15,94 & 14,82 \\
\hline Transporte, armazenagem e correio & 4,29 & 4,39 & 3,02 & 2,34 \\
\hline Alojamento e alimentação & 2,13 & 2,38 & 2,53 & 3,37 \\
\hline Informação e comunicação & 3,83 & 3,41 & 1,46 & 1,63 \\
\hline $\begin{array}{l}\text { Atividades financeiras, de seguros e serviços } \\
\text { relacionados }\end{array}$ & 6,80 & 7,09 & 2,58 & 2,98 \\
\hline Atividades imobiliárias & 8,31 & 9,68 & 8,03 & 9,11 \\
\hline $\begin{array}{l}\text { Atividades profissionais, científicas e técnicas, } \\
\text { administrativas e serviços complementares }\end{array}$ & 7,44 & 8,01 & 5,65 & 5,55 \\
\hline $\begin{array}{l}\text { Administração, defesa, educação e saúde públicas e } \\
\text { seguridade social }\end{array}$ & 16,28 & 17,18 & 33,02 & 33,21 \\
\hline Educação e saúde privadas & 3,00 & 4,07 & 2,29 & 3,02 \\
\hline $\begin{array}{l}\text { Artes, cultura, esporte e recreação e outras atividades } \\
\text { de serviços }\end{array}$ & 1,88 & 1,75 & 1,79 & 1,23 \\
\hline Serviços domésticos & 1,22 & 1,20 & 1,40 & 1,40 \\
\hline Total das Atividades & 100,0 & 100,0 & 100,0 & 100,0 \\
\hline
\end{tabular}

Fonte: Contas Regionais - IBGE. Elaboração própria. 
Do ponto de vista da participação das atividades no VAB nesse período, enquanto para o Brasil observou-se um acréscimo na participação relativa da atividade de comércio e reparação de veículos automotores e motocicletas, passando de 12,60\% do VAB total em 2010 para 13,30\% em 2015, comportamento oposto é verificado em âmbito estadual. Essa atividade declinou de uma participação de 15,94\% do VAB piauiense em 2010 para 14,82\% em 2015.

No que concerne à indústria extrativa como um todo, essa atividade declinou de uma participação de 0,72\% do VAB estadual em 2010 para 0,12\% em 2015. Comportamento similar é observado nacionalmente, redução participativa de 1,18 p.p. entre os anos analisados. Nesse mesmo período, a participação da indústria de transformação, como um todo, caiu nacionalmente de 14,97\% para $12,24 \%$ do $\mathrm{VAB}$, enquanto caiu de $5,20 \%$ para $4,24 \%$ no caso do VAB piauiense. Porém, a despeito de comportamento similar à indústria nacional, a indústria do Piauí mantém uma parcela da produção industrial total muito abaixo da média nacional. Esses resultados podem estar atrelados ao baixo desempenho da economia nacional nos anos de 2014 e de 2015, com o crescimento do PIB de aproximadamente $0,5 \%$ e $-3,8 \%$, respectivamente (IBGE, 2020).

Corroborando com o encontrado nos estudos de Botelho, Sousa e Avellar (2016) e de Souza (2016), há perda de participação das atividades ligadas à indústria de transformação no Piauí entre 2010 e 2015, com ganhos relativos para a agricultura e para alguns setores de serviços, como detalhado mais adiante, o que poderia ser indicativo de um processo de desindustrialização em curso, apesar de necessitar-se de um período superior a cinco anos para afirmarmos algo dessa natureza. Segundo o IBGE (2017a), o comportamento do emprego formal na indústria de transformação piauiense nesse período pode ser subdividido em dois, com fase de alta (crescimento de 12,82\%) entre 2010 e 2013 e subsequente queda até 2015, levando-nos a patamar próximo ao verificado em 2012.

No que tange à administração pública, essa aumentou sua participação no VAB nacional de 16,28\% para 17,18\%. Estadualmente, a participação dessa atividade na economia piauiense passou de 33,02\% em 2010 para 33,21\% do VAB estadual em 2015. Apesar de em ambos os casos se observar o aumento de sua participação entre os anos de 2010 e 2015, chama atenção a disparidade entre a participação dessa atividade no VAB nacional e piauiense. 
Chamam a atenção ainda os aumentos de participação no VAB estadual das atividades de alojamento e alimentação (3,37\% em 2015 ante 2,53\% em 2010), atividades financeiras, de seguros e serviços relacionados (de 2,58\% em 2010 para 2,98\% em 2015) e das atividades imobiliárias (de 8,03\% em 2010 para 9,11\% em 2015), bem como a queda de participação da atividade de construção (de 8,28\% em 2015 ante 8,38\% em 2010), as quais seguem a tendência nacional.

\section{Matriz insumo-produto piauiense: metodologia de estimação}

A modelagem trabalhada na mensuração das matrizes de insumo-produto de uma região diferencia-se em apenas alguns detalhes do modelo nacional. Neste caso, adicionam-se à MIP para uma região específica às exportações/importações inter-regionais (ou seja, o comércio com as demais regiões dentro do país). Logo, esses modelos possuem elaboração e tratamento mais delicados, uma vez que a escassez de dados é mais perceptível. Nas palavras de ten Raa (2005, p. 41), "inputoutput analysis focuses on the multiplier effects that stem from the "roundaboutness" in production, meaning that sectors use each other's outputs as inputs"4. Leontief (1986), por sua vez, trata a análise de insumo-produto como

A method of systematically quantifying the mutual interrelationships among the various sectors of a complex economic system. In practical terms, the economic system to which it is applied may be as large as a nation or even the entire world economy, or as small as the economy of a metropolitan area or even a single enterprise.

In all instances the approach is essentially the same. The structure of each sector's production process is represented by an appropriately defined vector of structural coefficients that describes in quantitative terms the relationship between the inputs it absorbs and the output it produces $^{5}$ (Leontief, 1986, p. 19).

Para a construção de uma matriz regional, alguns aspectos devem ser considerados. Guilhoto (2011) enfatiza que os principais dizem respeito à atualização dos valores e à regionalização dos coeficientes, caso o trabalho parta

\footnotetext{
${ }^{4}$ A análise de insumo-produto enfoca os efeitos multiplicadores que derivam da "rotatividade" na produção, o que significa que os setores usam os produtos uns dos outros como insumos (Tradução nossa).

${ }^{5}$ um método de quantificar sistematicamente as inter-relações mútuas entre os vários setores de um sistema econômico complexo. Em termos práticos, o sistema econômico ao qual ele é aplicado pode ser tão grande quanto uma nação ou mesmo a economia mundial inteira, ou tão pequena quanto a economia de uma área metropolitana ou até mesmo uma única empresa (Tradução nossa).

Em todos os casos, a abordagem é essencialmente a mesma. A estrutura do processo de produção de cada setor é representada por um vetor de coeficientes estruturais adequadamente definido que descreve em termos quantitativos a relação entre os insumos que absorve e o produto que produz (Tradução nossa).
} 
de uma matriz nacional. Dado que não há dados primários disponíveis para todos os coeficientes de uma matriz em termos regionais, a atualização e regionalização desses coeficientes não são possíveis através de uma mesma fonte de dados censitários. Nesse caso, Ribeiro e Leite (2012), assinalam, no que tange à metodologia de construção de matrizes regionais, a recomendação pela literatura internacional da adoção de métodos não-censitários, dentre os quais o método biproporcional RAS ${ }^{6}$.

Logo, lastreando-se na literatura, no que concerne à regionalização e atualização dos coeficientes técnicos para a matriz insumo-produto piauiense, optou-se pela utilização do método RAS. Assim, as estimativas para a matriz insumo-produto piauiense partiram da regionalização da matriz nacional, através de uma combinação de quocientes locacionais simples, que descrevem a concentração relativa da produção estadual, e regionalização das matrizes via RAS, proposto por Santos et al. (2020), que, por sua vez, consiste em aperfeiçoamento da metodologia utilizada em Leite (2016).

No que concerne aos dados utilizados, esses são provenientes de resultados de diferentes pesquisas realizadas pelo Instituto Brasileiro de Geografia e Estatística (IBGE). Para a confecção das matrizes nacionais, utilizadas como referência, para 2010 e 2015 - que constam em IBGE (2016, 2018b) - utiliza-se as Tabelas de Recursos e Usos (TRU), a preços básicos. As TRU, a partir de 2010, são divulgadas para 68 atividades econômicas e 128 produtos. São utilizados também os dados das Matrizes Insumo-Produto (MIP) Nacionais (2015 é a estimativa mais recente disponível), que também são parte integrante do Sistema de Contas Nacionais. As matrizes de 2010 e 2015, seguindo o nível de desagregação adotado para as TRU e agregando todas as atividades de comércio por atacado e varejo apresentam uma lista de 127 produtos e 67 atividades econômicas. Para aproximação à realidade estadual, duas fontes de dados são utilizadas: $i$ ) a primeira fonte consiste nas Contas Regionais do Brasil (IBGE, 2018a), que apresenta uma abertura para 18 atividades econômicas, a serem compatibilizadas com as matrizes nacionais de 2010 e 2015, com 67 atividades. Nesse caso, as Contas Regionais permitem acesso aos dados de valor bruto de produção, bem como do consumo intermediário dos estados brasileiros; ii) a

\footnotetext{
${ }^{6}$ Para uma descrição do método RAS tradicional vide Miller e Blair (2009, p. 313-338) e Bêrni et al. (2011). No contexto da regionalização de matrizes, vide Miller e Blair (2009, p. 360-363). Para uma apresentação mais completa das origens e aplicações do método, ver Lahr e De Mesnard (2004).
} 
segunda relaciona-se à Pesquisa Industrial Anual (IBGE, 2012, 2017b). A partir dela obtêm-se dados estaduais desagregados para empresas industriais com cinco ou mais pessoas ocupadas, possibilitando alguma abertura para a Indústria Extrativa e para a Indústria de Transformação, completamente agregadas nos dados das Contas Regionais.

Assim, conforme aponta Leite (2016, p. 137), a estimação de uma matriz insumo-produto para o estado do Piauí passa "pela integração entre os dados nacionais para as MIP e as Contas Regionais para o estado, essas últimas acrescidas da abertura propiciada pela Pesquisa Industrial Anual”.

No tocante ao procedimento adotado ${ }^{7}$, ao tomar-se uma matriz de produção nacional, $\mathbf{V}_{\mathrm{BR}}$, atividade por produto, há duas formas de obter os totais produzidos, de acordo com essas duas formas de classificação. Pode-se obter um vetor ${ }^{8}$ de produção total por atividade econômica, $\mathbf{g}_{\mathrm{BR}}$, a partir da operação $\mathbf{V}_{\mathrm{BR}}$. $\mathbf{i}$, com $\mathbf{i}$ sendo definido como um vetor-soma (cujos todos os elementos são iguais à unidade). Isto é, basta somar-se todas as colunas, ao longo de cada linha da matriz $\mathbf{V}_{\mathrm{BR}}$.

Similarmente, o total da produção em termos de produtos, $\mathbf{q}_{\mathrm{BR}}$, é obtido somando-se todas as linhas, ao longo de cada coluna da matriz $\mathbf{V}_{\mathrm{BR}}$ :

$$
\mathbf{q}_{\mathrm{BR}}=\left(\mathbf{i}^{\prime} \mathbf{V}_{\mathrm{BR}}\right)^{\prime}
$$

Diante de tais informações, pode-se obter uma matriz de parcela de mercado, $\mathbf{D}_{\mathrm{BR}}$, (matriz market-share), que expressa as proporções dos produtos gerados no âmbito de cada atividade. Instrumentalmente, a partir de $\mathbf{D}_{\mathrm{BR}}$, pode-se transformar matrizes classificadas em termos de produtos para atividades. Tal matriz pode ser assim definida:

$$
\mathbf{D}_{\mathrm{BR}}=\mathbf{V}_{\mathrm{BR}} \cdot \widehat{\mathrm{qBR}}^{-1}
$$

A partir de uma matriz de consumo intermediário nacional, $\mathbf{U}_{\mathrm{BR}}$, produto por atividade, é possível calcular a matriz de coeficientes técnicos nacionais, atividade por atividade:

\footnotetext{
${ }^{7}$ Convém denotar, a título de padronização do que se segue, que se utiliza subscritos BR para destacar as matrizes nacionais em contraposição às estaduais, as quais levarão subscritos PI. Ademais, vale ressaltar que se trabalha com todos os dados a preços básicos, isto é, excluídos margens de comércio e transportes e impostos líquidos de subsídios.

8 Tal como em Leite (2016), todos os vetores serão definidos como vetores-coluna, de modo que acrescentaremos o símbolo de transposição (') caso queiramos representar um vetor-linha e circunflexos para expressar vetores diagonalizados.
} 


$$
\mathbf{A}_{\mathrm{BR}}=\mathbf{D}_{\mathrm{BR}} \cdot \mathbf{U}_{\mathrm{BR}} \cdot \widehat{\mathbf{g}}^{-1}
$$

Por outro lado, define-se um vetor de demanda final ${ }^{9}$ reclassificado por atividade como:

$$
\mathbf{e}_{\mathrm{BR}}=\mathbf{D}_{\mathrm{BR}} \cdot \mathbf{f}_{\mathrm{BR}}
$$

Assim, diante da matriz de coeficientes técnicos e do vetor de demanda final, o sistema de Leontief poderia ser apresentado nos seguintes termos:

$$
\mathbf{A}_{\mathrm{BR}} \cdot \mathbf{g}_{\mathrm{BR}}+\mathbf{e}_{\mathrm{BR}}=\mathbf{g}_{\mathrm{BR}}
$$

Portanto:

$$
\mathbf{g}_{\mathrm{BR}}=\left(\mathbf{I}-\mathbf{A}_{\mathrm{BR}}\right)^{-1} \cdot \mathbf{e}_{\mathrm{BR}}
$$

Conforme mencionado previamente, no que tange à regionalização e atualização dos coeficientes técnicos para a matriz insumo-produto estadual, optou-se pela utilização do método RAS. Junius e Oosterhaven (2003) e Temurshoev, Miller e Bouwmeester (2013) trabalham com generalizações da técnica para o caso em que há tabelas com entradas negativas ${ }^{10}$. No presente trabalho, opta-se por uma aplicação mais simples em que um ajuste via RAS é aplicado para uma matriz de consumo intermediário, com entradas exclusivamente não-negativas.

Nesse caso, a partir da pós-multiplicação de um vetor de produção total diagonalizado pela matriz de coeficientes técnicos pode-se obter uma matriz de consumo intermediário nacional, $\mathbf{Q}_{\mathrm{BR}}$ :

$$
\mathbf{Q}_{\mathrm{BR}}=\mathbf{A}_{\mathrm{BR}} \cdot \widehat{\mathbf{g}_{\mathrm{BR}}}
$$

Conforme aponta Leite (2016), tal matriz possui as seguintes características: $i$ ) é uma matriz quadrada, atividade por atividade; $i i)$ expressa os insumos produzidos por uma atividade $i$ e demandados por uma atividade $j$ para consumo intermediário.

Da matriz de consumo intermediário nacional partem as estimativas para uma matriz $\mathbf{Q}_{\mathrm{PI}}$. Uma primeira estimativa para $\mathbf{Q}_{\mathrm{PI}}$ é dada supondo que a tecnologia de produção local é a mesma da média nacional, isto é, parte-se da

\footnotetext{
${ }^{9}$ Obtido pela soma de todos os componentes da demanda final, $\mathbf{f}_{\mathrm{BR}}=\mathbf{F}_{\mathrm{BR}} \cdot \mathbf{i}$.

10 Úteis em aplicações para as matrizes de demanda final, com valores negativos para a variação de estoques, ou para as tabelas de passagem de preços de consumidor para preços básicos, nas quais subsídios aparecem com valores negativos, por exemplo.
} 
matriz nacional para estimar-se uma matriz estadual. Assim, esse primeiro passo é dado por $^{11}$ :

$$
\mathbf{Q}_{\mathrm{PI} \_0}=\mathbf{A}_{\mathrm{BR}} \cdot \widehat{\mathbf{g P I}}
$$

No tocante ao vetor de produção total piauiense, $\mathbf{g}_{\mathrm{PI}}$, esse é fornecido a partir das Contas Regionais, acrescido da abertura fornecida pela Pesquisa Industrial Anual após a obtenção dos pesos das diferentes atividades industriais.

$\mathrm{O}$ vetor para o consumo intermediário (pelo destino), $\mathbf{c}_{\mathrm{PI}}$, também pode ser obtido diretamente das Contas Regionais. Nesse caso, para estimação do vetor de consumo intermediário a partir da produção estadual e, posteriormente, dar-se início à estimação de uma matriz de consumo intermediário regionalizada via RAS, usualmente parte-se da hipótese ${ }^{12}$ de que se o quociente locacional para uma atividade for maior ou igual a 1 , considera-se que a produção local é concentrada o bastante na atividade para suprir a totalidade do consumo intermediário requerido regionalmente, multiplicando-o, assim, por 1; caso contrário, multiplicase o consumo intermediário requerido regionalmente pelo próprio quociente locacional obtido.

No presente trabalho adota-se a hipótese variante ad hoc ${ }^{13}$ de que: i) a totalidade do consumo intermediário é suprida regionalmente apenas para quocientes locacionais maiores ou iguais a 2 ; ii) $80 \%$ do consumo intermediário é produzido regionalmente se os quocientes locacionais estiverem entre 1 e 2; e, iii) $80 \%$ do consumo intermediário deve ser multiplicado pelo quociente locacional correspondente nos demais casos.

Em relação ao vetor da produção (pela origem) destinada ao consumo intermediário, $\mathbf{m}_{\mathrm{PI}}$, esse é estimado por:

$$
\begin{gathered}
\mathbf{m}_{\mathrm{PI} \_0}=\mathbf{Q}_{\mathrm{PI} \_0 \cdot \mathbf{i}} \\
\mathbf{m}_{\mathrm{PI}}=\mathbf{m}_{\mathrm{PI} \_0} \cdot \frac{\mathbf{i}^{\prime} \cdot \mathbf{c}_{\mathrm{PI}}}{\mathbf{i}^{\prime} \cdot \mathbf{m}_{\mathrm{PI} \_}}
\end{gathered}
$$

\footnotetext{
${ }^{11}$ Após o PI, o subscrito indica o passo correspondente à estimativa via método RAS (utiliza-se 0 para a estimativa anterior ao início do processo iterativo).

${ }^{12}$ Utiliza-se uma variante de hipótese bastante difundida na literatura. Vide Szabó (2015, p. 51) e Miller e Blair (2009, p. 350), por exemplo.

${ }^{13}$ Essa variante foi adotada considerando-se que, sob as hipóteses usuais (produção suprida localmente para $Q L>1$ ), a matriz de consumo intermediário estadual estimada não se mostrava compatível com um vetor de demanda final estadual com entradas exclusivamente não negativas.
} 
Diante dessas informações, o ajuste via método RAS tem início. Formalmente, a primeira rodada do balanceamento biproporcional é feita ajustando cada elemento ao longo das linhas da matriz de consumo intermediário estadual provisória, em (8), utilizando um primeiro vetor de ajuste $\mathbf{r}$ :

$$
\begin{aligned}
& \mathbf{r}_{1}=\widehat{\mathbf{m}}_{\mathrm{PI} \_0}{ }^{-1} \cdot \mathbf{m}_{\mathrm{PI}} \\
& \mathbf{Q}_{\mathrm{PI} \_1 \mathrm{r}}=\widehat{\mathbf{r}_{1}} \cdot \mathbf{Q}_{\mathrm{PI} 0}
\end{aligned}
$$

Realizado o primeiro passo do balanceamento, obtém-se uma nova estimativa, por meio de um vetor $\mathbf{s}$, a partir do ajuste das colunas:

$$
\begin{gathered}
\mathbf{s}_{1}=\left(\mathbf{i}^{\prime} \cdot \widehat{\mathrm{QPI}_{\mathrm{PI}} \mathrm{r}}\right)^{-1} \cdot \mathbf{c}_{\mathrm{PI}} \\
\mathbf{Q}_{\mathrm{PI} 1 \mathrm{~s}}=\mathbf{Q}_{\mathrm{PI} 1 \mathrm{r}} \cdot \widehat{\mathbf{s}_{1}}
\end{gathered}
$$

Dando mais um passo tem-se:

$$
\begin{gathered}
\mathbf{r}_{2}=\left(\widehat{\mathrm{Q}_{\mathrm{PI} \_1 s}} \cdot \mathbf{i}\right)^{-1} \cdot \mathbf{m}_{\mathrm{PI}} \\
\mathbf{Q}_{\mathrm{PI} \_\mathrm{r}}=\widehat{\mathbf{r}_{2}} \cdot \mathbf{Q}_{\mathrm{PI} 1 \mathrm{~s}} \\
\mathbf{s}_{2}=\left(\mathbf{i}^{\prime} \cdot \widehat{\mathrm{Q}_{\mathrm{PI} 2 \mathrm{r}}}\right)^{-1} \mathbf{c}_{\mathrm{PI}} \\
\mathbf{Q}_{\mathrm{PI} 2 \mathrm{~s}}=\mathbf{Q}_{\mathrm{PI} 2 \mathrm{r}} \cdot \widehat{\mathbf{s}_{2}}
\end{gathered}
$$

Esse processo iterativo se segue indefinidamente até assegurar-se que $\mathbf{r}_{\mathrm{n}}=$ $\mathbf{s}_{\mathrm{n}}=\mathbf{i}$. Alternativamente, o processo segue até que a matriz $\mathbf{Q}_{\mathrm{PI}}$ convirja, isto é, $\mathbf{Q}_{\mathrm{PI} \text { r }}=\mathbf{Q}_{\mathrm{PI} \text { s }}$. Após o cálculo da estimativa final para $\mathbf{Q}_{\mathrm{PI}}$, pode-se calcular a matriz de coeficientes técnicos e a inversa de Leontief, em uma versão estadual, as quais são dadas por:

$$
\begin{gathered}
\mathbf{A}_{\mathrm{PI}}=\mathbf{Q}_{\mathrm{PI}} \cdot \widehat{\mathbf{g}}_{\mathrm{PI}}^{-1} \\
\left(\mathbf{I}-\mathbf{A}_{\mathrm{PI}}\right)^{-1}
\end{gathered}
$$

Logo, o cálculo de indicadores relacionados também pode ser efetuado.

No que concerne ao grau de abertura, para 2010 e 2015, mesmos anos das MIPs nacionais e, por isso, tomados para a regionalização, por não haver desidentificação em atividades relevantes, foi possível trabalhar-se com 40 atividades. À exceção de Fabricação de Outros Equipamentos de Transporte, para ambos os anos analisados, da Fabricação de Produtos do Fumo para 2010 e das atividades de Refino de Petróleo, Coquerias e Biocombustíveis e Fabricação de Equipamentos de Informática, Produtos Eletrônicos e Ópticos para 2015, com 
somente duas empresas respondentes e apresentando uma participação muito pequena na produção estadual ${ }^{14}$, para a Indústria de Transformação, a desagregação possível foi de 23 atividades, 7 a menos na comparação à MIP nacional. As informações das empresas da Indústria Extrativa piauiense não permitiram à desagregação da atividade. Logo, a matriz piauiense, no que tange à Indústria Extrativa, possui 3 atividades a menos que o disponível para a MIP nacional. Para as atividades restantes, ao manter-se o nível de agregação das Contas Regionais, tem-se 17 atividades a menos que a MIP nacional, resultando numa abertura para 40 atividades, ao invés das 67 possíveis no plano nacional, conforme exposto na Tabela 3.

\footnotetext{
${ }^{14}$ Apurada por resíduo entre o total da Indústria de Transformação e a soma de todas as outras atividades que a compõem. Utiliza-se, nesse caso, a proporção nacional entre as atividades para chegar-se às participações estaduais.
} 


\section{Tabela 3 - Lista de agregação de 67 para 40 atividades}

\begin{tabular}{|c|c|}
\hline \multicolumn{2}{|c|}{ Atividade } \\
\hline 1 Agricultura, inclusive o apoio à agricultura e a pós-colheita & 1 Agricultura, inclusive o apoio à agricultura e a pós-colheita \\
\hline 2 Pecuária, inclusive o apoio à pecuária & 2 Pecuária, inclusive o apoio à pecuária \\
\hline 3 Produção florestal; pesca e aquicultura & 3 Produção florestal; pesca e aquicultura \\
\hline 4 Extração de carvão mineral e de minerais não-metálicos & 4 Extração mineral (4 a 7) \\
\hline 5 Extração de petróleo e gás, inclusive as atividades de apoio & 5 Alimentos (8 a 10) \\
\hline 6 Extração de minério de ferro, inclusive beneficiamentos e a aglomeração & 6 Fabricação de bebidas \\
\hline 7 Extração de minerais metálicos não-ferrosos, inclusive beneficiamentos & 7 Fabricação de produtos do fumo \\
\hline 8 Abate e produtos de carne, inclusive os produtos do laticínio e da pesca & 8 Fabricação de produtos têxteis \\
\hline 9 Fabricação e refino de açúcar & 9 Confecção de artefatos do vestuário e acessórios \\
\hline 10 Outros produtos alimentares & 10 Fabricação de calçados e de artefatos de couro \\
\hline 11 Fabricação de bebidas & 11 Fabricação de produtos da madeira \\
\hline 12 Fabricação de produtos do fumo & 12 Fabricação de celulose, papel e produtos de papel \\
\hline 13 Fabricação de produtos têxteis & 13 Impressão e reprodução de gravações \\
\hline 14 Confecção de artefatos do vestuário e acessórios & 14 Refino de petróleo e coquerias e biocombustíveis $(19+20)$ \\
\hline 15 Fabricação de calçados e de artefatos de couro & 15 Químicos em geral (21 a 23) \\
\hline 16 Fabricação de produtos da madeira & 16 Fabricação de produtos farmoquímicos e farmacêuticos \\
\hline 17 Fabricação de celulose, papel e produtos de papel & 17 Fabricação de produtos de borracha e de material plástico \\
\hline 18 Impressão e reprodução de gravações & 18 Fabricação de produtos de minerais não-metálicos \\
\hline 19 Refino de petróleo e coquerias & 19 Siderurgia e metalurgia $(27+28)$ \\
\hline 20 Fabricação de biocombustíveis & 20 Fabricação de produtos de metal, exceto máquinas e equipamentos \\
\hline 21 Fabricação de químicos orgânicos e inorgânicos, resinas e elastômeros & 21 Fabricação de equipamentos de informática, produtos eletrônicos e ópticos \\
\hline 22 Fabricação de defensivos, desinfestantes, tintas e químicos diversos & 22 Fabricação de máquinas e equipamentos elétricos \\
\hline 23 Fabricação de produtos de limpeza, cosméticos/perfumaria e higiene pessoal & 23 Fabricação de máquinas e equipamentos mecânicos \\
\hline 24 Fabricação de produtos farmoquímicos e farmacêuticos & 24 Automóveis e autopeças $(33+34)$ \\
\hline 25 Fabricação de produtos de borracha e de material plástico & 25 Fabricação de outros equipamentos de transporte, exceto veículos automotores \\
\hline 26 Fabricação de produtos de minerais não-metálicos & 26 Fabricação de móveis e de produtos de indústrias diversas \\
\hline 27 Produção de ferro-gusa/ferroligas, siderurgia e tubos de aço sem costura & 27 Manutenção, reparação e instalação de máquinas e equipamentos \\
\hline 28 Metalurgia de metais não-ferosos e a fundição de metais & 28 Serviços de utilidade pública $(38+39)$ \\
\hline 29 Fabricação de produtos de metal, exceto máquinas e equipamentos & 29 Construção \\
\hline 30 Fabricação de equipamentos de informática, produtos eletrônicos e ópticos & 30 Comércio por atacado e varejo \\
\hline 31 Fabricação de máquinas e equipamentos elétricos & 31 Transporte, armazenagem e correios ( 42 a 45$)$ \\
\hline 32 Fabricação de máquinas e equipamentos mecânicos & 32 Alojamento e Alimentação $(46$ + 47) \\
\hline 33 Fabricação de automóveis, caminhões e ônibus, exceto peças & 33 Serviços de comunicação e informação (48 a 51) \\
\hline 34 Fabricação de peças e acessórios para veículos automotores & 34 Intermediação financeira, seguros e previdência complementar \\
\hline 35 Fabricação de outros equipamentos de transporte, exceto veículos automotores & 35 Atividades imobiliárias \\
\hline 36 Fabricação de móveis e de produtos de indústrias diversas & 36 Serviços prestados a empresas (54 a 59) \\
\hline 37 Manutenção, reparação e instalação de máquinas e equipamentos & 37 Administração, educação e saúde públicas \\
\hline 38 Energia elétrica, gás natural e outras utilidades & 38 Educação e saúde privadas \\
\hline 39 Água, esgoto e gestão de resíduos & 39 Outros serviços pessoais $(65+66)$ \\
\hline 40 Construção & 40 Serviços domésticos \\
\hline 41 Comércio por atacado e varejo & \\
\hline 42 Transporte terrestre & \\
\hline 43 Transporte aquaviário & \\
\hline 44 Transporte aéreo & \\
\hline 45 Armazenamento, atividades auxiliares dos transportes e correio & \\
\hline 46 Alojamento & \\
\hline 47 Alimentação & \\
\hline 48 Edição e edição integrada à impressão & \\
\hline 49 Atividades de televisão, rádio, cinema e gravação/edição de som e imagem & \\
\hline 50 Telecomunicações & \\
\hline 51 Desenvolvimento de sistemas e outros serviços de informação & \\
\hline 52 Intermediação financeira, seguros e previdência complementar & \\
\hline 53 Atividades imobiliárias & \\
\hline 54 Atividades jurídicas, contábeis, consultoria e sedes de empresas & \\
\hline 55 Serviços de arquitetura, engenharia, testes/análises técnicas e P \& D & \\
\hline 56 Outras atividades profissionais, científicas e técnicas & \\
\hline 57 Aluguéis não-imobiliários e gestão de ativos de propriedade intelectual & \\
\hline 58 Outras atividades administrativas e serviços complementares & \\
\hline 59 Atividades de vigilância, segurança e investigação & \\
\hline 60 Administração pública, defesa e seguridade social & \\
\hline 61 Educação pública & \\
\hline 62 Educação privada & \\
\hline 63 Saúde pública & \\
\hline 64 Saúde privada & \\
\hline 65 Atividades artísticas, criativas e de espetáculos & \\
\hline 66 Organizações associativas e outros serviços pessoais & \\
\hline 67 Serviços domésticos & \\
\hline
\end{tabular}

Fonte: IBGE. Elaboração própria. 


\section{Indicadores estruturais}

A partir da matriz de insumo-produto piauiense, mediante análise da estrutura produtiva ${ }^{15}$ local, dos encadeamentos produtivos entre as atividades do estado e dos seus setores-chave, diversas métricas que podem ser utilizadas como parâmetros para a tomada de decisões de políticas públicas podem ser tecidas. Nesse sentido, a presente seção tem por objetivo apresentar os principais resultados obtidos para os indicadores estruturais da economia piauiense.

\subsection{Quocientes locacionais}

Os quocientes locacionais ${ }^{16}$ descrevem a concentração de determinada atividade no Piauí a partir da comparação com a produção no resto do país. A partir de dois vetores de produção total, por atividade, um nacional e outro para o estado, os quocientes locacionais são obtidos através da divisão entre as proporções da produção estadual por atividade e as proporções da produção nacional por atividade:

$$
\mathbf{Q} \mathbf{L}=\left(\frac{\widehat{\mathbf{g}_{\mathrm{BR}}}}{\mathbf{i}^{\prime} \mathbf{g}_{\mathrm{BR}}}\right)^{-1} \cdot\left(\frac{\mathbf{g}_{\mathrm{PI}}}{\mathbf{i}^{\prime} \mathbf{g}_{\mathrm{PI}}}\right)
$$

Basicamente, acima de 1, o quociente locacional indica que a produção de determinado setor está relativamente concentrada no estado em comparação à média nacional. Isto posto, abaixo de 1 , o quociente locacional indica que a produção é pouco concentrada estadualmente naquela atividade. A Tabela 4 revela as medidas dos quocientes locacionais que indicam a concentração de cada uma das atividades, comparadas à média nacional nos anos de 2010 e 2015.

No ano de 2010, observou-se que, das 40 atividades produtivas analisadas para o Piauí, 13 apresentavam-se concentradas, quando comparadas à média nacional $(Q L>1)$. São elas: Fabricação de Bebidas; Administração, Educação e Saúde Públicas; Produção Florestal; Pesca e Aquicultura; Construção; Agricultura, Inclusive o Apoio à Agricultura e a Pós-Colheita; Comércio por Atacado e Varejo; Pecuária, Inclusive o Apoio à Pecuária; Serviços Domésticos; Fabricação de Produtos de Minerais Não-Metálicos; Serviços de Utilidade Pública; Alojamento e Alimentação; Atividades Imobiliárias e; Outros Serviços Pessoais.

\footnotetext{
${ }^{15}$ Para maior aprofundamento das análises estruturais, ver Kurz et al. (1998); Lahr e Dietzenbacher (2001) e Hewings et al. (2002).

${ }^{16} \mathrm{O}$ debate acerca do uso dos quocientes simples, bem como de algumas de suas variantes, pode ser encontrado em Flegg et al. (1995), Jiang et al. (2012), Szabó (2015), ou, ainda, em Miller e Blair (2009, p. 349-358).
} 
Tabela 4 - Quocientes locacionais para o Piauí (2010 e 2015)

\begin{tabular}{|c|c|c|c|}
\hline & Atividade & 2010 & 2015 \\
\hline 1 & Agricultura, inclusive o apoio à agricultura e a pós-colheita & 1,46 & 2,12 \\
\hline 2 & Pecuária, inclusive o apoio à pecuária & 1,43 & 1,25 \\
\hline 3 & Produção florestal; pesca e aquicultura & 1,92 & 2,20 \\
\hline 4 & Extração mineral & 0,24 & 0,06 \\
\hline 5 & Alimentos & 0,96 & 0,80 \\
\hline 6 & Fabricação de bebidas & 3,42 & 1,88 \\
\hline 7 & Fabricação de produtos do fumo & 0,46 & 0,001 \\
\hline 8 & Fabricação de produtos têxteis & 0,08 & 0,14 \\
\hline 9 & Confecção de artefatos do vestuário e acessórios & 0,37 & 0,39 \\
\hline & Fabricação de calçados e de artefatos de couro & 0,27 & 0,34 \\
\hline & Fabricação de produtos da madeira & 0,06 & 0,06 \\
\hline 12 & Fabricação de celulose, papel e produtos de papel & 0,004 & 0,06 \\
\hline 13 & Impressão e reprodução de gravações & 0,67 & 0,67 \\
\hline 14 & Refino de petróleo e coquerias e biocombustíveis & 0,04 & 0,04 \\
\hline 15 & Químicos em geral & 0,12 & 0,09 \\
\hline 16 & Fabricação de produtos farmoquímicos e farmacêuticos & 0,19 & 0,16 \\
\hline 17 & Fabricação de produtos de borracha e de material plástico & 0,20 & 0,17 \\
\hline 18 & Fabricação de produtos de minerais não-metálicos & 1,27 & 0,78 \\
\hline 19 & Siderurgia e metalurgia & 0,30 & 0,47 \\
\hline 20 & Fabricação de produtos de metal, exceto máquinas e equipamentos & 0,13 & 0,47 \\
\hline 21 & Fabricação de equipamentos de informática, produtos eletrônicos e ópticos & 0,01 & 0,05 \\
\hline 22 & Fabricação de máquinas e equipamentos elétricos & 0,27 & 0,18 \\
\hline 23 & Fabricação de máquinas e equipamentos mecânicos & 0,04 & 0,06 \\
\hline 24 & Automóveis e autopeças & 0,02 & 0,02 \\
\hline 25 & Fabricação de outros equipamentos de transporte, exceto veículos automotores & 0,46 & 0,05 \\
\hline 26 & Fabricação de móveis e de produtos de indústrias diversas & 0,65 & 0,52 \\
\hline 27 & Manutenção, reparação e instalação de máquinas e equipamentos & 0,01 & 0,04 \\
\hline & Serviços de utilidade pública & 1,25 & 1,05 \\
\hline & Construção & 1,71 & 1,81 \\
\hline & Comércio por atacado e varejo & 1,44 & 1,28 \\
\hline & Transporte, armazenagem e correios & 0,79 & 0,70 \\
\hline & Alojamento e alimentação & 1,16 & 1,42 \\
\hline 33 & Serviços de comunicação e informação & 0,50 & 0,32 \\
\hline & Intermediação financeira, seguros e previdência complementar & 0,45 & 0,50 \\
\hline 35 & Atividades imobiliárias & 1,14 & 1,17 \\
\hline 36 & Serviços prestados a empresas & 0,71 & 0,71 \\
\hline & Administração, educação e saúde públicas & 2,31 & 2,23 \\
\hline & Educação e saúde privadas & 0,95 & 0,93 \\
\hline & Outros serviços pessoais & 1,13 & 0,81 \\
\hline & Serviços domésticos & 1,37 & 1,42 \\
\hline
\end{tabular}

Fonte: elaboração própria.

Traçando um comparativo entre os anos analisados, para 2015, notou-se uma redução de dois setores produtivos concentrados $(Q L<1)$ : Fabricação de Produtos de Minerais Não-Metálicos $(0,78)$ e Outros Serviços Pessoais $(0,81)$, passando de 13 para 11 atividades. Além disso, de 2010 para 2015 houve mudanças no nível dos $Q L s$, onde a Fabricação de Bebidas deixa de ser a atividade produtiva com maior $Q L$, dando lugar à Administração, Educação e Saúde Públicas (que permaneceu praticamente constante). Em termos de aumento da concentração, destacam-se a Produção Florestal, Pesca e Aquicultura; e o Apoio à Agricultura e a Pós-Colheita ( $Q L>2$ em ambas). 


\subsection{Multiplicadores de produção}

Os multiplicadores são estimações de quanto a geração de algum fator na economia implica na geração de outros fatores (Guilhoto, 2011). Trata-se, portanto, de um indicador que capta os efeitos diretos e indiretos de produção, dada a matriz de coeficientes técnicos estadual.

Formalmente, para o caso nacional e piauiense, os multiplicadores simples de produção são dados por:

$$
\begin{aligned}
\mathbf{M P}_{\mathrm{BR}} & =\mathbf{i}^{\prime}\left(\mathbf{I}-\mathbf{A}_{\mathrm{BR}}\right)^{-1} \\
\mathbf{M P}_{\mathrm{PI}} & =\mathbf{i}^{\prime}\left(\mathbf{I}-\mathbf{A}_{\mathrm{PI}}\right)^{-1}
\end{aligned}
$$

A Tabela 5 mostra os resultados estimados dos multiplicadores de produção para o Piauí nos anos de 2010 e 2015. Em nível estadual, dentre os multiplicadores de produção encontrados, nenhum superou aqueles estimados em âmbito nacional ${ }^{17}$.

Excluindo-se as atividades desidentificadas na Pesquisa Industrial Anual, de acordo com os resultados apresentados na Tabela 5 para o ano de 2010, a atividade de Alimentos foi considerada a atividade com maior encadeamento de produção tanto para o Brasil quanto para o estado do Piauí. Quanto a este último, dado o incremento de um milhão de reais na demanda final da atividade de Alimentos, estima-se que $\mathrm{R} \$ 720.000$ (setecentos e vinte mil) sejam gerados em termos de VBP em toda economia piauiense. Para o caso do Brasil, o VBP gerado seria de $\mathrm{R} \$ 1.420 .000$ (um milhão, quatrocentos e vinte mil).

\footnotetext{
${ }^{17}$ Miller e Blair (2009) apontam que uma discussão recorrente na estimação de matrizes regionais diz respeito à superestimação dos coeficientes regionais. Seja porque os coeficientes importados podem ser maiores em determinadas regiões ou por qualquer outro motivo mais geral que nos leve a crer que o ajuste via quocientes locacionais não é suficiente, o que nos levaria a superestimar também os multiplicadores regionais de produção. Todavia, nenhum dos multiplicadores estimados para o Piauí superou aqueles estimados em âmbito nacional.
} 
Tabela 5 - Multiplicadores de produção para o Brasil e Piauí (2010 e 2015)

\begin{tabular}{|c|c|c|c|c|}
\hline \multirow{2}{*}{ Atividade } & \multicolumn{2}{|c|}{2010} & \multicolumn{2}{|c|}{2015} \\
\hline & BR & PI & BR & PI \\
\hline 1 Agricultura, inclusive o apoio à agricultura e a pós-colheita & 1,67 & 1,29 & 1,73 & 1,28 \\
\hline 2 Pecuária, inclusive o apoio à pecuária & 1,77 & 1,26 & 1,79 & 1,23 \\
\hline 3 Produção florestal; pesca e aquicultura & 1,37 & 1,18 & 1,36 & 1,16 \\
\hline 4 Extração mineral & 1,61 & 1,21 & 1,76 & 1,26 \\
\hline 5 Alimentos & 2,42 & 1,72 & 2,43 & 1,53 \\
\hline 6 Fabricação de bebidas & 2,15 & 1,23 & 2,19 & 1,30 \\
\hline 7 Fabricação de produtos do fumo & 2,21 & 1,52 & 2,17 & 1,20 \\
\hline 8 Fabricação de produtos têxteis & 2,09 & 1,35 & 2,02 & 1,35 \\
\hline 9 Confecção de artefatos do vestuário e acessórios & 1,81 & 1,35 & 1,85 & 1,28 \\
\hline 10 Fabricação de calçados e de artefatos de couro & 2,08 & 1,64 & 2,08 & 1,55 \\
\hline 11 Fabricação de produtos da madeira & 1,90 & 1,37 & 1,95 & 1,37 \\
\hline 12 Fabricação de celulose, papel e produtos de papel & 2,14 & 1,34 & 2,03 & 1,38 \\
\hline 13 Impressão e reprodução de gravações & 1,88 & 1,45 & 1,83 & 1,21 \\
\hline 14 Refino de petróleo e coquerias e biocombustíveis & 2,33 & 1,27 & 2,50 & 1,38 \\
\hline 15 Químicos em geral & 2,10 & 1,36 & 2,04 & 1,29 \\
\hline 16 Fabricação de produtos farmoquímicos e farmacêuticos & 1,69 & 1,36 & 1,76 & 1,36 \\
\hline 17 Fabricação de produtos de borracha e de material plástico & 2,06 & 1,47 & 2,02 & 1,42 \\
\hline 18 Fabricação de produtos de minerais não-metálicos & 2,03 & 1,35 & 2,10 & 1,38 \\
\hline 19 Siderurgia e metalurgia & 2,20 & 1,57 & 2,14 & 1,55 \\
\hline 20 Fabricação de produtos de metal, exceto máquinas e equipamentos & 2,01 & 1,38 & 1,97 & 1,54 \\
\hline 21 Fabricação de equipamentos de informática, produtos eletrônicos e ópticos & 1,68 & 1,05 & 1,68 & 1,22 \\
\hline 22 Fabricação de máquinas e equipamentos elétricos & 2,12 & 1,53 & 2,07 & 1,54 \\
\hline 23 Fabricação de máquinas e equipamentos mecânicos & 1,97 & 1,43 & 1,87 & 1,37 \\
\hline 24 Automóveis e autopeças & 2,19 & 1,59 & 2,15 & 1,42 \\
\hline 25 Fabricação de outros equipamentos de transporte, exceto veículos automotores & 1,92 & 1,39 & 1,92 & 1,31 \\
\hline 26 Fabricação de móveis e de produtos de indústrias diversas & 1,83 & 1,49 & 1,81 & 1,39 \\
\hline 27 Manutenção, reparação e instalação de máquinas e equipamentos & 1,78 & 1,20 & 1,75 & 1,09 \\
\hline 28 Serviços de utilidade pública & 1,79 & 1,45 & 1,95 & 1,54 \\
\hline 29 Construção & 1,83 & 1,35 & 1,80 & 1,31 \\
\hline 30 Comércio por atacado e varejo & 1,52 & 1,19 & 1,54 & 1,19 \\
\hline 31 Transporte, armazenagem e correios & 1,87 & 1,31 & 1,89 & 1,33 \\
\hline 32 Alojamento e alimentação & 1,78 & 1,23 & 1,81 & 1,35 \\
\hline 33 Serviços de comunicação e informação & 1,69 & 1,32 & 1,63 & 1,63 \\
\hline 34 Intermediação financeira, seguros e previdência complementar & 1,52 & 1,22 & 1,49 & 1,20 \\
\hline 35 Atividades imobiliárias & 1,09 & 1,03 & 1,11 & 1,05 \\
\hline 36 Serviços prestados a empresas & 1,51 & 1,11 & 1,48 & 1,14 \\
\hline 37 Administração, educação e saúde públicas & 1,42 & 1,16 & 1,38 & 1,13 \\
\hline 38 Educação e saúde privadas & 1,56 & 1,26 & 1,48 & 1,21 \\
\hline 39 Outros serviços pessoais & 1,68 & 1,28 & 1,65 & 1,25 \\
\hline 40 Serviços domésticos & 1,00 & 1,00 & 1,00 & 1,00 \\
\hline
\end{tabular}

Fonte: elaboração própria.

Para o ano de 2015, embora o setor de Alimentos ainda seja um dos mais importantes, o cenário muda tanto para o Brasil quanto para o Piauí. No caso do primeiro, o Refino de Petróleo e Coquerias e Biocombustíveis foi constatado com aquele que mais gerou Valor Bruto da Produção $(2,50)$. A interpretação desse multiplicador denota que, para cada um milhão de reais incrementado nesse setor, estima-se um VBP gerado de aproximadamente $\mathrm{R} \$ 1.500 .000$ (um milhão e 
quinhentos mil reais). No caso do Piauí, a atividade de Serviços de Comunicação e Informação, por esse critério, foi considerada como atividade chave, gerando um VBP adicional de $\mathrm{R} \$ 630.000$ (seiscentos e trinta mil reais).

As demais atividades da economia piauiense no ano de 2015 que geraram VBP acima de quinhentos mil reais foram: Siderurgia e Metalurgia; Fabricação de Calçados e de Artefatos de Couro; Fabricação de Máquinas e Equipamentos Elétricos; Serviços de Utilidade Pública; Fabricação de Produtos de Metal, Exceto Máquinas e Equipamentos e; Alimentos.

Contudo, tal qual o observado por Leite (2016) e Santos, Costa e Leite (2020) para o estado do Rio Grande do Norte, quando se compara a estrutura produtiva estadual com a nacional percebe-se algumas carências. A indústria de transformação piauiense possui baixos multiplicadores se comparados à indústria nacional, o que revela o caráter pouco encadeado da indústria do estado. Logo, os efeitos de transbordamento do crescimento para o estado, provenientes de aumentos na demanda final nacional pelas atividades com elevadas ligações para trás pouco afetariam a produção estadual.

\subsection{Indicadores de Rasmussen-Hirschman}

A Tabela 6 apresenta os indicadores de Rasmussen-Hirschman $(B L)$, encadeamentos a montante, para o Piauí comparado ao nacional, com a finalidade de se perceber quais atividades possuem encadeamentos abaixo ou acima da média nacional. Formalmente, o indicador é dado por:

$$
\mathbf{B L}_{\mathrm{BR}}=n \times \frac{\mathbf{i}^{\prime}\left(\mathbf{I}-\mathbf{A}_{\mathrm{BR}}\right)^{-1}}{\mathbf{i}^{\prime}\left(\mathbf{I}-\mathbf{A}_{\mathrm{BR}}\right)^{-1} \cdot \mathbf{i}}
$$

Ao considerarmos a produção nacional, e

$$
\mathbf{B L}_{\mathrm{PI}}=n \times \frac{\mathbf{i}^{\prime}\left(\mathbf{I}-\mathbf{A}_{\mathrm{PI}}\right)^{-1}}{\mathbf{i}^{\prime}\left(\mathbf{I}-\mathbf{A}_{\mathrm{PI}}\right)^{-1} \cdot \mathbf{i}},
$$

Ao tomarmos a produção estadual.

Esses indicadores também são conhecidos na literatura como poder de dispersão e, como uma medida normalizada, o ranqueamento entre as atividades a partir desse indicador deve ser o mesmo que se encontraria tomando os multiplicadores de produção como referência. A vantagem do uso dessa medida normalizada está na fácil identificação de quais atividades apresentam 
encadeamentos acima da média, isto é, com poder de dispersão maior que 1 , e quais atividades apresentam encadeamentos abaixo da média, poder de dispersão inferior a 1 .

\section{Tabela 6 - Indicadores de Rasmussen-Hirschman a montante (BL) para o Brasil e PI (2010 e 2015)}

\begin{tabular}{|c|c|c|c|c|}
\hline \multirow{2}{*}{ Atividade } & \multicolumn{2}{|c|}{2010} & \multicolumn{2}{|c|}{2015} \\
\hline & $\mathbf{B R}$ & $\mathbf{P I}$ & $\mathbf{B R}$ & $\mathbf{P I}$ \\
\hline 1 Agricultura, inclusive o apoio à agricultura e a pós-colheita & 0,91 & 0,97 & 0,94 & 0,97 \\
\hline 2 Pecuária, inclusive o apoio à pecuária & 0,97 & 0,95 & 0,98 & 0,93 \\
\hline 3 Produção florestal; pesca e aquicultura & 0,75 & 0,89 & 0,74 & 0,88 \\
\hline 4 Extração mineral & 0,88 & 0,91 & 0,96 & 0,95 \\
\hline 5 Alimentos & 1,32 & 1,29 & 1,33 & 1,16 \\
\hline 6 Fabricação de bebidas & 1,17 & 0,92 & 1,20 & 0,98 \\
\hline 7 Fabricação de produtos do fumo & 1,20 & 1,14 & 1,19 & 0,91 \\
\hline 8 Fabricação de produtos têxteis & 1,14 & 1,01 & 1,10 & 1,03 \\
\hline 9 Confecção de artefatos do vestuário e acessórios & 0,99 & 1,02 & 1,01 & 0,98 \\
\hline 10 Fabricação de calçados e de artefatos de couro & 1,13 & 1,23 & 1,14 & 1,17 \\
\hline 11 Fabricação de produtos da madeira & 1,04 & 1,03 & 1,07 & 1,04 \\
\hline 12 Fabricação de celulose, papel e produtos de papel & 1,17 & 1,01 & 1,11 & 1,05 \\
\hline 13 Impressão e reprodução de gravações & 1,03 & 1,09 & 1,00 & 0,92 \\
\hline 14 Refino de petróleo e coquerias e biocombustíveis & 1,27 & 0,96 & 1,36 & 1,05 \\
\hline 15 Químicos em geral & 1,15 & 1,02 & 1,11 & 0,98 \\
\hline 16 Fabricação de produtos farmoquímicos e farmacêuticos & 0,92 & 1,02 & 0,96 & 1,03 \\
\hline 17 Fabricação de produtos de borracha e de material plástico & 1,13 & 1,10 & 1,11 & 1,08 \\
\hline 18 Fabricação de produtos de minerais não-metálicos & 1,11 & 1,01 & 1,15 & 1,05 \\
\hline 19 Siderurgia e metalurgia & 1,20 & 1,18 & 1,17 & 1,17 \\
\hline 20 Fabricação de produtos de metal, exceto máquinas e equipamentos & 1,10 & 1,04 & 1,08 & 1,17 \\
\hline 21 Fabricação de equipamentos de informática, produtos eletrônicos e ópticos & 0,92 & 0,79 & 0,92 & 0,92 \\
\hline 22 Fabricação de máquinas e equipamentos elétricos & 1,16 & 1,15 & 1,13 & 1,17 \\
\hline 23 Fabricação de máquinas e equipamentos mecânicos & 1,07 & 1,07 & 1,02 & 1,04 \\
\hline 24 Automóveis e autopeças & 1,19 & 1,19 & 1,18 & 1,08 \\
\hline 25 Fabricação de outros equipamentos de transporte, exceto veículos automotores & 1,05 & 1,04 & 1,05 & 1,00 \\
\hline 26 Fabricação de móveis e de produtos de indústrias diversas & 1,00 & 1,12 & 0,99 & 1,05 \\
\hline 27 Manutenção, reparação e instalação de máquinas e equipamentos & 0,97 & 0,90 & 0,96 & 0,83 \\
\hline 28 Serviços de utilidade pública & 0,98 & 1,09 & 1,07 & 1,17 \\
\hline 29 Construção & 1,00 & 1,01 & 0,98 & 1,00 \\
\hline 30 Comércio por atacado e varejo & 0,83 & 0,90 & 0,84 & 0,90 \\
\hline 31 Transporte, armazenagem e correios & 1,02 & 0,98 & 1,03 & 1,01 \\
\hline 32 Alojamento e alimentação & 0,97 & 0,92 & 0,99 & 1,02 \\
\hline 33 Serviços de comunicação e informação & 0,92 & 0,99 & 0,89 & 1,24 \\
\hline 34 Intermediação financeira, seguros e previdência complementar & 0,83 & 0,92 & 0,81 & 0,91 \\
\hline 35 Atividades imobiliárias & 0,60 & 0,77 & 0,61 & 0,80 \\
\hline 36 Serviços prestados a empresas & 0,82 & 0,84 & 0,81 & 0,86 \\
\hline 37 Administração, educação e saúde públicas & 0,77 & 0,87 & 0,76 & 0,86 \\
\hline 38 Educação e saúde privadas & 0,85 & 0,94 & 0,81 & 0,92 \\
\hline 39 Outros serviços pessoais & 0,92 & 0,96 & 0,90 & 0,95 \\
\hline 40 Serviços domésticos & 0,55 & 0,75 & 0,55 & 0,76 \\
\hline
\end{tabular}

Fonte: elaboração própria.

Em nível nacional, as cinco atividades produtivas com maiores encadeamentos à montante no ano de 2010 foram: Alimentos; Refino de Petróleo e Coquerias e Biocombustíveis; Fabricação de Produtos do Fumo; Siderurgia e 
Metalurgia; e Automóveis e Autopeças. No estado do Piauí essas atividades também possuem os maiores encadeamentos, exceto para o caso do Refino de Petróleo e Coquerias e Biocombustíveis. Além dessas quatro, estadualmente, destaca-se a atividade de Fabricação de Calçados e de Artefatos de Couro (sendo a terceira de maior encadeamento no estado).

Em 2015 o cenário permanece praticamente o mesmo em nível nacional. A atividade de Alimentos continua como a de maior encadeamento para trás, seguida pelo Refino de Petróleo e Coquerias e Biocombustíveis. No entanto, a atividade de Siderurgia e Metalurgia deixa de ser uma das cinco atividades de maior encadeamento, caindo para o sexto lugar. As outras três, entre as cinco primeiras foram: Fabricação de Bebidas; Fabricação de Produtos do Fumo; e Automóveis e Autopeças.

Quanto ao Piauí em 2015, as cinco atividades de maior encadeamento à montante são: Alimentos; Serviços de Comunicação e Informação; Siderurgia e Metalurgia; Fabricação de Calçados e de Artefatos de Couro; e Fabricação de Máquinas e Equipamentos Elétricos. Dito isso, pode-se concluir que a concentração da economia piauiense, em 2015, distancia-se em certa ordem das atividades produtivas de altos encadeamentos em nível nacional.

No tocante aos encadeamentos a jusante (forward linkages, $F L$ ) esses são calculados, no presente trabalho, a partir da reespecificação de um modelo de Ghosh ${ }^{18}$ pelo lado da oferta. Nesse caso, de forma análoga à equação 3 , podemos definir:

$$
\mathbf{B}_{\mathrm{BR}}={\widehat{\mathbf{g}_{\mathrm{BR}}}}^{-1} \cdot \mathbf{D}_{\mathrm{BR}} \cdot \mathbf{U}_{\mathrm{BR}}
$$

A partir da inversa de Ghosh, respectivamente, para a produção nacional e estadual, uma medida normalizada dos encadeamentos para frente será dada por:

$$
\begin{aligned}
\mathbf{F L}_{\mathrm{BR}} & =n \times \frac{\left(\mathbf{I}-\mathbf{B}_{\mathrm{BR}}\right)^{-1} \mathbf{i}}{\mathbf{i}^{\prime}\left(\mathbf{I}-\mathbf{B}_{\mathrm{BR}}\right)^{-1} \cdot \mathbf{i}} \\
\mathbf{F L}_{\mathrm{PI}} & =n \times \frac{\left(\mathbf{I}-\mathbf{B}_{\mathrm{PI}}\right)^{-1} \mathbf{i}}{\mathbf{i}^{\prime}\left(\mathbf{I}-\mathbf{B}_{\mathrm{PI}}\right)^{-1} \cdot \mathbf{i}}
\end{aligned}
$$

Das 40 atividades analisadas para o Piauí, em 2010, 17 possuíam encadeamento a jusante maior que 1 . Dessas 17 atividades, 16 também possuíam encadeamento para frente maior que 1 em âmbito nacional. Em 2015, também observa-se que 17

\footnotetext{
${ }^{18}$ Vide Miller e Blair (2009, cap. 12) para uma especificação completa do modelo de Ghosh.
} 
atividades em nível estadual apresentaram encadeamentos para frente maior que 1, dessas 15 também apresentaram FL maior que 1 no cenário nacional.

\section{Tabela 7 - Indicadores de Rasmussen-Hirschman a jusante (FL) para o Brasil e PI (2010 e 2015)}

\begin{tabular}{|c|c|c|c|c|}
\hline \multirow{2}{*}{ Atividade } & \multicolumn{2}{|c|}{2010} & \multicolumn{2}{|c|}{2015} \\
\hline & $\mathbf{B R}$ & $\mathbf{P I}$ & $\mathbf{B R}$ & PI \\
\hline 1 Agricultura, inclusive o apoio à agricultura e a pós-colheita & 1,05 & 1,01 & 0,99 & 0,90 \\
\hline 2 Pecuária, inclusive o apoio à pecuária & 1,11 & 1,10 & 1,14 & 1,09 \\
\hline 3 Produção florestal; pesca e aquicultura & 1,16 & 0,89 & 1,03 & 0,89 \\
\hline 4 Extração mineral & 1,26 & 0,88 & 1,34 & 0,86 \\
\hline 5 Alimentos & 0,79 & 0,96 & 0,81 & 0,93 \\
\hline 6 Fabricação de bebidas & 0,88 & 0,94 & 0,92 & 1,00 \\
\hline 7 Fabricação de produtos do fumo & 0,62 & 0,77 & 0,59 & 0,74 \\
\hline 8 Fabricação de produtos têxteis & 1,06 & 0,88 & 1,12 & 0,92 \\
\hline 9 Confecção de artefatos do vestuário e acessórios & 0,68 & 0,84 & 0,69 & 0,84 \\
\hline 10 Fabricação de calçados e de artefatos de couro & 0,68 & 0,78 & 0,68 & 0,78 \\
\hline 11 Fabricação de produtos da madeira & 1,19 & 1,20 & 1,19 & 1,20 \\
\hline 12 Fabricação de celulose, papel e produtos de papel & 1,26 & 1,07 & 1,13 & 1,02 \\
\hline 13 Impressão e reprodução de gravações & 1,59 & 1,49 & 1,59 & 1,44 \\
\hline 14 Refino de petróleo e coquerias e biocombustíveis & 1,43 & 1,07 & 1,51 & 1,04 \\
\hline 15 Químicos em geral & 1,39 & 1,14 & 1,42 & 1,25 \\
\hline 16 Fabricação de produtos farmoquímicos e farmacêuticos & 0,74 & 0,95 & 0,76 & 0,94 \\
\hline 17 Fabricação de produtos de borracha e de material plástico & 1,32 & 1,19 & 1,37 & 1,20 \\
\hline 18 Fabricação de produtos de minerais não-metálicos & 1,29 & 1,52 & 1,30 & 1,72 \\
\hline 19 Siderurgia e metalurgia & 1,30 & 0,98 & 1,15 & 1,01 \\
\hline 20 Fabricação de produtos de metal, exceto máquinas e equipamentos & 1,21 & 1,19 & 1,23 & 1,23 \\
\hline 21 Fabricação de equipamentos de informática, produtos eletrônicos e ópticos & 0,74 & 0,82 & 0,73 & 0,80 \\
\hline 22 Fabricação de máquinas e equipamentos elétricos & 0,97 & 1,01 & 1,00 & 1,01 \\
\hline 23 Fabricação de máquinas e equipamentos mecânicos & 0,86 & 0,82 & 0,84 & 0,82 \\
\hline 24 Automóveis e autopeças & 0,80 & 0,82 & 0,81 & 0,83 \\
\hline 25 Fabricação de outros equipamentos de transporte, exceto veículos automotores & 0,71 & 0,81 & 0,74 & 0,78 \\
\hline 26 Fabricação de móveis e de produtos de indústrias diversas & 0,74 & 0,90 & 0,74 & 0,90 \\
\hline 27 Manutenção, reparação e instalação de máquinas e equipamentos & 1,50 & 1,22 & 1,44 & 1,18 \\
\hline 28 Serviços de utilidade pública & 1,30 & 1,26 & 1,34 & 1,36 \\
\hline 29 Construção & 0,69 & 0,84 & 0,69 & 0,84 \\
\hline 30 Comércio por atacado e varejo & 0,94 & 0,91 & 0,94 & 0,93 \\
\hline 31 Transporte, armazenagem e correios & 1,27 & 1,22 & 1,30 & 1,19 \\
\hline 32 Alojamento e alimentação & 0,73 & 0,92 & 0,72 & 0,86 \\
\hline 33 Serviços de comunicação e informação & 1,15 & 1,12 & 1,12 & 1,08 \\
\hline 34 Intermediação financeira, seguros e previdência complementar & 1,05 & 1,14 & 1,06 & 1,13 \\
\hline 35 Atividades imobiliárias & 0,70 & 0,85 & 0,69 & 0,83 \\
\hline 36 Serviços prestados a empresas & 1,38 & 1,37 & 1,38 & 1,33 \\
\hline 37 Administração, educação e saúde públicas & 0,58 & 0,75 & 0,58 & 0,75 \\
\hline 38 Educação e saúde privadas & 0,65 & 0,82 & 0,64 & 0,80 \\
\hline 39 Outros serviços pessoais & 0,71 & 0,83 & 0,73 & 0,84 \\
\hline 40 Serviços domésticos & 0,55 & 0,74 & 0,56 & 0,74 \\
\hline
\end{tabular}

Fonte: elaboração própria.

Calculadas as medidas de encadeamento para trás e para frente para o estado do Piauí podemos representá-las graficamente por meio da Figura 1. 
Figura 1 - Indicação de setores-chave para o Piauí em 2010 e 2015
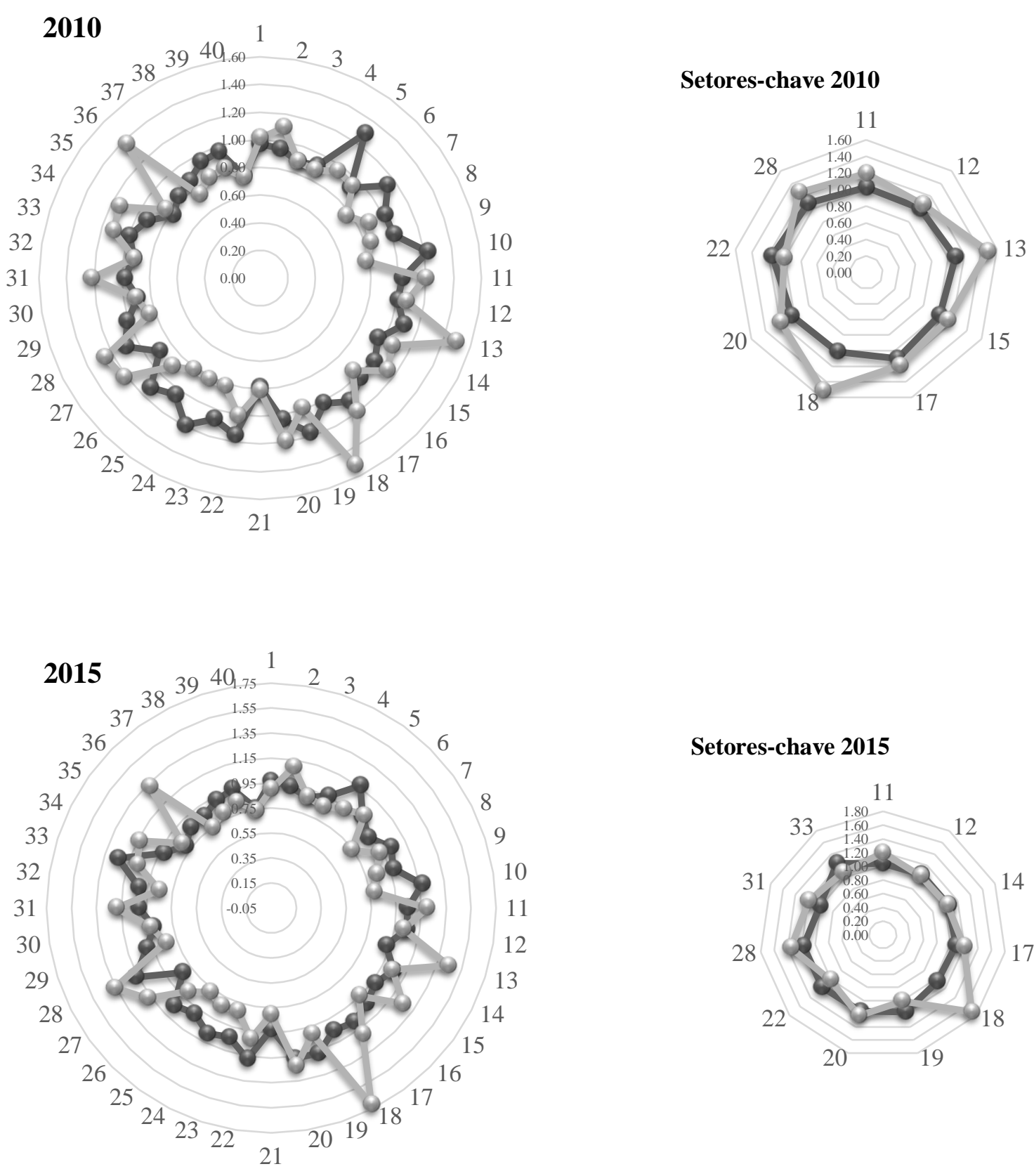

Setores-chave 2015

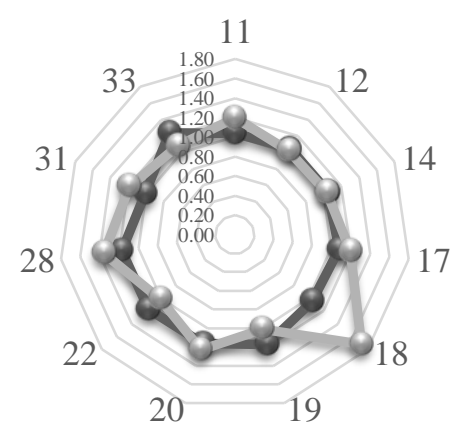

\section{-Encadeam entos para trás $\quad-$ Encadeam entos para frente}

Fonte: elaboração própria.

Como pode-se notar, não são muitas as atividades piauienses que, simultaneamente, apresentam encadeamentos acima da média tanto para trás quanto para frente nos respectivos anos analisados. 
Em 2010, do conjunto de 10 atividades que apresentaram os maiores multiplicadores de produção, somente as atividades de Fabricação de Produtos de Borracha e de Material Plástico, Impressão e Reprodução de Gravações e Serviços de Utilidade Pública, respectivamente, oitava, nona e décima atividade com mais encadeamentos à montante, também satisfazem o critério de apresentar encadeamentos à jusante acima da média. A atividade classificada com o maior encadeamento para trás, Alimentos (8), destaca-se mais pelo potencial de demandar insumos, ou seja, pelos encadeamentos para trás, do que pelos encadeamentos para frente. O contrário ocorre com a atividade 18, Fabricação de Produtos de Minerais Não-Metálicos.

Para 2015, 11 atividades do estado, 2 a mais no comparativo com 2010, apresentaram encadeamentos acima da média tanto para trás quanto para frente. Impressão e Reprodução de Gravações, segundo maior encadeamento para frente em 2015, figuram na lista das atividades-chave para 2010, porém, deixa de ser considerada chave em 2015. Comportamento similar é observado para a atividade de Químicos em Geral, quinto maior encadeamento a jusante em 2015. Dentre os casos de melhora relativa nas medidas de encadeamento para o período observado, de modo a serem consideradas atividades-chave para 2015, temos Refino de Petróleo e Coquerias e Biocombustíveis, Siderurgia e Metalurgia, Transporte, Armazenagem e Correios e Serviços de Comunicação e Informação.

\subsection{Extração Hipotética}

Segundo Leite (2016), os mais variados métodos de mensuração devem ser estimados para explicarem não apenas o quanto cada setor gera na economia regional como um todo, mas também o impacto que um, isoladamente, gera sobre os demais. Nesse caso, alternativamente, pode-se analisar a importância de cada atividade no total da produção por meio do artifício da extração hipotética ${ }^{19}$ de cada atividade econômica, o qual visa estimar que diferença faria, em termos de perda, a ausência de cada uma das atividades para a produção total da economia analisada, fornecendo uma medida que mistura encadeamentos à montante e à jusante.

Das equações expostas em (5) e (6), tem-se que, do ponto de vista piauiense:

\footnotetext{
${ }^{19}$ Para maiores informações vide Cella (1984), Clements (1990), Dietzenbacher e Van Der Linden, (1997) e Miller e Blair (2009).
} 


$$
\mathbf{A}_{\mathrm{PI}} \cdot \mathbf{g}_{\mathrm{PI}}+\mathbf{e}_{\mathrm{PI}}=\mathbf{g}_{\mathrm{PI}}
$$

Logo,

$$
\mathbf{g}_{\mathrm{PI}}=\left(\mathbf{I}-\mathbf{A}_{\mathrm{PI}}\right)^{-1} \cdot \mathbf{e}_{\mathrm{PI}}
$$

Operacionalmente, o método de extração hipotética suprime ${ }^{20}$ a linha e a coluna relativas à determinada atividade da matriz de coeficientes técnicos. Nesse caso, utiliza-se uma matriz de extração, denotada por $\mathbf{X}_{\mathbf{j}}$, com as mesmas dimensões da matriz de coeficientes técnicos. Tal matriz de extração é similar a uma matriz identidade em todas as suas colunas, exceto a coluna relativa à atividade $\mathbf{j}$ selecionada para a extração hipotética, que será substituída por um vetor formado por zeros. Assim, formalmente, respectivamente para o Brasil e para o Piauí, tem-se:

$$
\begin{aligned}
\mathbf{j}_{\mathrm{BR}} & =\left(\mathbf{I}-\mathbf{X}_{\mathrm{j}_{-} \mathrm{BR}} \cdot \mathbf{A}_{\mathrm{BR}} \cdot \mathbf{X}_{\mathrm{j}_{-} \mathrm{BR}}\right)^{-1} \cdot \mathbf{X}_{\mathrm{j}_{-} \mathrm{BR}} \cdot \mathbf{e}_{\mathrm{BR}} \\
\mathbf{j}_{\mathrm{PI}} & =\left(\mathbf{I}-\mathbf{X}_{\mathrm{j}_{-} \mathrm{PI}} \cdot \mathbf{A}_{\mathrm{PI}} \cdot \mathbf{X}_{\mathrm{j}_{-} \mathrm{PI}}\right)^{-1} \cdot \mathbf{X}_{\mathrm{j}_{-} \mathrm{PI}} \cdot \mathbf{e}_{\mathrm{PI}}
\end{aligned}
$$

A partir de (31) e (32), obtém-se um vetor de produção total que desconsidera toda a influência da atividade selecionada na produção do sistema econômico nacional e piauiense. Assim, para o cálculo da perda com a extração de cada atividade nacional e estadual, realiza-se, respectivamente, a seguinte operação:

$$
\begin{aligned}
& \frac{\mathbf{i}^{\prime} \cdot \mathbf{g}_{\mathrm{BR}}-\mathbf{i}^{\prime} \cdot \mathbf{j}_{\mathrm{BR}}}{\mathbf{i}^{\prime} \cdot \mathbf{g}_{\mathrm{BR}}} \\
& \frac{\mathbf{i}^{\prime} \cdot \mathbf{g}_{\mathrm{PI}}-\mathbf{i}^{\prime} \cdot \mathbf{j}_{\mathrm{PI}}}{\mathbf{i}^{\prime} \cdot \mathbf{g}_{\mathrm{PI}}}
\end{aligned}
$$

Portanto, a partir de (33) e (34) calcula-se, para cada atividade, a perda proporcional em termos de produção total caso a atividade seja excluída do sistema econômico, e, consequentemente, todos os elos da cadeia que ela faz parte. $\mathrm{Na}$ Tabela 8 estão dispostos os resultados encontrados.

\footnotetext{
${ }^{20}$ Alternativamente, podemos fazer com que as linhas e as colunas relativas à atividade sejam formadas somente por zeros.
} 
Tabela 8 - Perda percentual da produção total com extração hipotética para o Brasil e Piauí (2010 e 2015)

\begin{tabular}{|c|c|c|c|c|}
\hline \multirow{2}{*}{ Atividade } & \multicolumn{2}{|c|}{2010} & \multicolumn{2}{|c|}{2015} \\
\hline & $\mathbf{B R}$ & PI & BR & PI \\
\hline 1 Agricultura, inclusive o apoio à agricultura e a pós-colheita & $4,14 \%$ & $4,62 \%$ & $5,07 \%$ & $7,82 \%$ \\
\hline 2 Pecuária, inclusive o apoio à pecuária & $2,13 \%$ & $2,22 \%$ & $2,28 \%$ & $1,99 \%$ \\
\hline 3 Produção florestal; pesca e aquicultura & $0,40 \%$ & $0,66 \%$ & $0,41 \%$ & $0,77 \%$ \\
\hline 4 Extração mineral & $4,56 \%$ & $0,85 \%$ & $4,16 \%$ & $0,18 \%$ \\
\hline 5 Alimentos & $10,62 \%$ & $7,42 \%$ & $11,26 \%$ & $6,14 \%$ \\
\hline 6 Fabricação de bebidas & $1,52 \%$ & $3,02 \%$ & $1,44 \%$ & $1,68 \%$ \\
\hline 7 Fabricação de produtos do fumo & $0,41 \%$ & $0,14 \%$ & $0,31 \%$ & $0,0003 \%$ \\
\hline 8 Fabricação de produtos têxteis & $1,04 \%$ & $0,06 \%$ & $0,75 \%$ & $0,08 \%$ \\
\hline 9 Confecção de artefatos do vestuário e acessórios & $1,28 \%$ & $0,360 \%$ & $1,06 \%$ & $0,30 \%$ \\
\hline 10 Fabricação de calçados e de artefatos de couro & $0,78 \%$ & $0,19 \%$ & $0,71 \%$ & $0,20 \%$ \\
\hline 11 Fabricação de produtos da madeira & $0,53 \%$ & $0,02 \%$ & $0,45 \%$ & $0,02 \%$ \\
\hline 12 Fabricação de celulose, papel e produtos de papel & $1,54 \%$ & $0,005 \%$ & $1,43 \%$ & $0,07 \%$ \\
\hline 13 Impressão e reprodução de gravações & $0,46 \%$ & $0,23 \%$ & $0,33 \%$ & $0,15 \%$ \\
\hline 14 Refino de petróleo e coquerias e biocombustíveis & $6,21 \%$ & $0,21 \%$ & $6,67 \%$ & $0,25 \%$ \\
\hline 15 Químicos em geral & $4,13 \%$ & $0,39 \%$ & $4,12 \%$ & $0,30 \%$ \\
\hline 16 Fabricação de produtos farmoquímicos e farmacêuticos & $1,02 \%$ & $0,16 \%$ & $0,98 \%$ & $0,12 \%$ \\
\hline 17 Fabricação de produtos de borracha e de material plástico & $1,99 \%$ & $0,31 \%$ & $1,75 \%$ & $0,23 \%$ \\
\hline 18 Fabricação de produtos de minerais não-metálicos & $1,77 \%$ & $1,54 \%$ & $1,66 \%$ & $0,88 \%$ \\
\hline 19 Siderurgia e metalurgia & $3,67 \%$ & $0,90 \%$ & $2,95 \%$ & $1,08 \%$ \\
\hline 20 Fabricação de produtos de metal, exceto máquinas e equipamentos & $2,14 \%$ & $0,20 \%$ & $1,62 \%$ & $0,62 \%$ \\
\hline 21 Fabricação de equipamentos de informática, produtos eletrônicos e ópticos & $1,49 \%$ & $0,01 \%$ & $1,26 \%$ & $0,05 \%$ \\
\hline 22 Fabricação de máquinas e equipamentos elétricos & $1,71 \%$ & $0,35 \%$ & $1,33 \%$ & $0,19 \%$ \\
\hline 23 Fabricação de máquinas e equipamentos mecânicos & $2,61 \%$ & $0,09 \%$ & $2,02 \%$ & $0,09 \%$ \\
\hline 24 Automóveis e autopeças & $6,32 \%$ & $0,09 \%$ & $3,77 \%$ & $0,05 \%$ \\
\hline 25 Fabricação de outros equipamentos de transporte, exceto veículos automotores & $0,82 \%$ & $0,30 \%$ & $0,83 \%$ & $0,03 \%$ \\
\hline 26 Fabricação de móveis e de produtos de indústrias diversas & $1,37 \%$ & $0,72 \%$ & $1,23 \%$ & $0,49 \%$ \\
\hline 27 Manutenção, reparação e instalação de máquinas e equipamentos & $1,12 \%$ & $0,01 \%$ & $1,05 \%$ & $0,03 \%$ \\
\hline 28 Serviços de utilidade pública & $4,10 \%$ & $4,24 \%$ & $4,42 \%$ & $3,82 \%$ \\
\hline 29 Construção & $11,16 \%$ & $14,26 \%$ & $10,05 \%$ & $13,56 \%$ \\
\hline 30 Comércio por atacado e varejo & $14,31 \%$ & $16,43 \%$ & $15,80 \%$ & $16,02 \%$ \\
\hline 31 Transporte, armazenagem e correios & $7,81 \%$ & $4,45 \%$ & $8,09 \%$ & $4,12 \%$ \\
\hline 32 Alojamento e alimentação & $3,79 \%$ & $3,04 \%$ & $4,37 \%$ & $4,63 \%$ \\
\hline 33 Serviços de comunicação e informação & $5,38 \%$ & $2,35 \%$ & $4,83 \%$ & $1,66 \%$ \\
\hline 34 Intermediação financeira, seguros e previdência complementar & $7,26 \%$ & $2,87 \%$ & $7,27 \%$ & $3,22 \%$ \\
\hline 35 Atividades imobiliárias & $4,90 \%$ & $5,26 \%$ & $5,90 \%$ & $6,52 \%$ \\
\hline 36 Serviços prestados a empresas & $8,02 \%$ & $4,55 \%$ & $8,43 \%$ & $4,91 \%$ \\
\hline 37 Administração, educação e saúde públicas & $16,01 \%$ & $30,19 \%$ & $16,28 \%$ & $29,86 \%$ \\
\hline 38 Educação e saúde privadas & $3,77 \%$ & $2,92 \%$ & $4,51 \%$ & $3,49 \%$ \\
\hline 39 Outros serviços pessoais & $3,19 \%$ & $2,76 \%$ & $2,86 \%$ & $1,77 \%$ \\
\hline 40 Serviços domésticos & $0,61 \%$ & $0,84 \%$ & $0,61 \%$ & $0,86 \%$ \\
\hline
\end{tabular}

Fonte: elaboração própria.

Constata-se, a partir da Tabela 8, que a retirada da Administração, Educação e Saúde Públicas implicaria significativas perdas da produção total da economia brasileira e piauiense nos anos de 2010 e 2015. Nesse primeiro ano, na ausência dessa atividade, o esperado seria uma redução na produção total de 16,01\%, Brasil, e 30,19\%, Piauí. Para 2015, a perda seria de 16,28\% e 29,86\%, respectivamente. Outras atividades cuja retirada implicariam importantes perdas em termos de VBP do Piauí nesses anos foram: Comércio por Atacado e Varejo; 
Construção; Alimentos; Atividades Imobiliárias; Serviços Prestados a Empresas; Transporte, Armazenagem e Correios; Serviços de Utilidade Pública; e Alojamento e Alimentação.

Por outro lado, em âmbito nacional nesse dois anos, os setores menos importantes em termos de impacto negativo aos demais foram: Produção Florestal, Pesca e Aquicultura; Fabricação de Produtos do Fumo; Impressão e Reprodução de Gravações; Fabricação de Produtos da Madeira; Serviços Domésticos; Fabricação de Calçados e de Artefatos de Couro; Fabricação de Produtos Têxteis; Fabricação de Outros Equipamentos de Transporte, Exceto Veículos Automotores; e Fabricação de Produtos Farmoquímicos e Farmacêuticos.

Já para o caso do Piauí nesses dois anos, existe um caso particular, pois à exceção da Administração, Educação e Saúde Públicas, a grande maioria das atividades, isoladamente, não impactariam em grande escala em termos de queda percentual de VBP.

\section{Considerações finais}

O presente artigo buscou estimar uma Matriz de Insumo-Produto regionalizada para o Piauí, com abertura para 40 atividades produtivas do estado, destacando aquelas com maiores participações em termos de Valor Bruto da Produção estadual e, ainda, comparando seus resultados com os apresentados em nível nacional.

Entre os resultados encontrados, pode-se destacar que o exercício da extração hipotética denota que as atividades de Alimentos, Administração, Educação e Saúde Públicas, Comércio por Atacado e Varejo, Construção e de Serviços de Comunicação e Informação lograriam maiores perdas de Valor Bruto de Produção na economia piauiense. Outras atividades importantes dessa economia, que combinam, em ambos os anos analisados, encadeamentos para trás e para frente maior que a média são: Fabricação de Produtos da Madeira, Fabricação de Celulose, Papel e Produtos de Papel, Fabricação de Produtos de Borracha e de Material Plástico, Fabricação de Produtos de Minerais NãoMetálicos, Fabricação de Produtos de Metal, Exceto Máquinas e Equipamentos, Fabricação de Máquinas e Equipamentos Elétricos e Serviços de Utilidade Pública.

No comparativo à estrutura produtiva nacional, percebe-se algumas carências da economia piauiense. A indústria de transformação do estado possui baixos 
multiplicadores se comparados à indústria nacional, o que revela o caráter pouco encadeado da indústria local. Logo, os efeitos de transbordamento do crescimento para o Piauí, provenientes de aumentos na demanda final nacional pelas atividades com elevadas ligações para trás pouco afetariam a produção piauiense.

Ademais, pode-se perceber que a representatividade do Piauí no VBP nacional ainda é tímida. Com isso, é importante que trabalhos como este sejam desenvolvidos para que os agentes públicos possam ter uma base clara sobre os principais setores de sua economia - seja na produção e na geração de emprego e renda, seja na inter-relação entre os setores - e como devem atuar para que suas decisões contribuam de maneira mais incisiva sobre o crescimento econômico estadual.

Assim, a partir do momento em que os gestores públicos (principalmente) sabem quais setores têm maior efeito multiplicador na economia local, as políticas de incentivo e, inclusive, de alocação de recursos às atividades produtivas passam a contar com um guia mais objetivo para que as decisões sejam eficientemente tomadas.

Dessa forma, acredita-se que a partir do relacionamento conjunto entre os poderes público (na elaboração de incentivos aos setores-chave citados anteriormente) e privado, é possível desenvolver e/ou otimizar as atividades produtivas e as relações de dependência de uns para com os outros, impactando, principalmente, na geração de emprego, de renda e de bens/serviços de maior valor agregado.

\section{Referências}

BÊRNI, D.; LAUTERT, V. Mesoeconomia: lições de contabilidade social. Porto Alegre: Bookman, 2011.

BOTELHO, M.; SOUSA, G.; AVELLAR, A. A incidência do processo de desindustrialização nos estados brasileiros. Revista de Economia, v. 43, n. 3, p. 1-26, 2016.

CELLA, G. The input-output measurement of interindustry linkages. Oxford Bulletin of Economics and Statistics, v. 46, n. 1, p. 73-84, 1984.

CLEMENTS, B. On the decomposition and normalization of interindustry linkages. Economics Letters, v. 33, n. 4, p. 337-340, 1990. 
DIETZENBACHER, E.; VAN DER LINDEN, J. A. Sectoral and spatial linkages in the EC production structure. Journal of Regional Science, v. 37, n. 2, p. 235-257, 1997.

FLEGG, A.; WEBER, C.; ELLIOT, M. On the appropriate use of location quotients in generating regional input-output tables. Regional Studies, v. 29, n. 6, p. 547-561, 1995.

GUILHOTO, J. Análise de insumo-produto: teoria e fundamentos. São Paulo: mimeo, 2011.

GUILHOTO, J.; AZZONI, C.; ICHIHARA, S.; KADOTA, D.; HADDAD, E. Matriz de insumo-produto do Nordeste e estados: metodologia e resultados. Fortaleza: Banco do Nordeste do Brasil, 2010.

GUILHOTO, J. Leontief e insumo-produto: antecedentes, princípios e evolução. Munich Personal RePEc Archive, n. 54649, 2014.

HADDAD, E.; GONÇALVES JÚNIOR, C.; NASCIMENTO, T. Matriz interestadual de insumo-produto para o Brasil: uma aplicação do método IIOAS. Revista Brasileira de Estudos Regionais e Urbanos, v. 11, n. 4, p. 424-446, 2018.

HEWINGS, G; SONIS, M.; BOYCE, D. Trade, networks and hierarchies: modeling regional and inter-regional economies. Berlim: Springer, 2002.

INSTITUTO BRASILEIRO DE GEOGRAFIA E ESTATÍSTICA - IBGE. Cadastro Central de Empresas 2015. Rio de Janeiro, IBGE, 2017a.

INSTITUTO BRASILEIRO DE GEOGRAFIA E ESTATÍSTICA - IBGE. Contas Nacionais Trimestrais. Rio de Janeiro, IBGE, 2020.

INSTITUTO BRASILEIRO DE GEOGRAFIA E ESTATÍSTICA - IBGE. Contas Regionais do Brasil: 2010-2016, Contas Nacionais, v. 64, Rio de Janeiro, IBGE, 2018a.

INSTITUTO BRASILEIRO DE GEOGRAFIA E ESTATÍSTICA - IBGE. Matriz de insumo-produto: Brasil 2010, Contas Nacionais, v. 51, Rio de Janeiro, IBGE, 2016.

INSTITUTO BRASILEIRO DE GEOGRAFIA E ESTATÍSTICA - IBGE. Matriz de insumo-produto: Brasil 2015, Contas Nacionais, v. 62, Rio de Janeiro, IBGE, $2018 b$. 
INSTITUTO BRASILEIRO DE GEOGRAFIA E ESTATÍSTICA - IBGE. Pesquisa Industrial Anual: Empresas 2010. Pesquisa Industrial, v. 29, n. 1, Rio de Janeiro, IBGE, 2012.

INSTITUTO BRASILEIRO DE GEOGRAFIA E ESTATÍSTICA - IBGE. Pesquisa Industrial Anual: Empresas 2015, Pesquisa Industrial, v. 34, n. 1, Rio de Janeiro, IBGE, $2017 \mathrm{~b}$.

JIANG, X.; DIETZENBACHER, E.; LOS, B. Improved estimation of regional input-output tables using cross-regional methods. Regional Studies, v. 46, n. 5, p. 621-637, 2012.

JUNIUS, T.; OOSTERHAVEN, J. The solution of updating or regionalizing a matrix with both positive and negative entries. Economic Systems Research, v. 15, p. 87-96, 2003.

KURZ, H.; DIETZENBACHER, E.; LAGER, C. Input-output analysis. Cheltenham: Edward Elgar, 1998.

LAHR, M.; DE MESNARD, L. Biproportional techniques in input-output analysis: table updating and structural analysis. Economic Systems Research, v. 16, n. 2, p. 115-134, 2004.

LAHR, M.; DIETZENBACHER, E. Input-output analysis: frontiers and extensions. Houndmills: Palgrave, 2001.

LEITE, A.; PEREIRA, R. Matriz insumo-produto da economia baiana: uma análise estrutural e subsídios às políticas de planejamento. Revista Desenbahia, v. 7, p. 99-134, 2010.

LEITE, F. Estrutura de produção do Rio Grande do Norte: estimativas a partir de matrizes insumo-produto. In: PEREIRA, W.; SILVA, M.; ARAÚJO, D. (Org.). Recortes analíticos sobre desenvolvimento, estado e economia do Rio Grande do Norte. Natal: Edufrn, p. 131-173, 2016.

LEONTIEF, W. Input-Output economics. Nova Iorque: Oxford University Press, 1986.

MILLER, R.; BLAIR, P. Input-output analysis: foundations and extensions. Nova Iorque: Cambridge University Press, 2009.

PEROBELLI, F.; VALE, V.; PIRES, M. Estimativa da Matriz de Insumo-Produto da Bahia (2009): características sistêmicas da estrutura produtiva do Estado. Revista Econômica do Nordeste, v. 46, n. 4, p. 97-115, 2015. 
RIBEIRO, L.; LEITE, A. Análise estrutural dos investimentos do PAC em infraestrutura logística no estado da Bahia. Revista Análise Econômica, v. 32, n. 62, p. 125-154, 2014.

RIBEIRO, L.; LEITE, A. Estrutura econômica do estado de Sergipe em 2006: uma contribuição através da matriz de insumo-produto. Revista Econômica do Nordeste, v. 43, n. 4, p. 95-117, 2012.

RIBEIRO, L.; MONTENEGRO, R.; PEREIRA, R. Estrutura econômica e encadeamentos setoriais de Minas Gerais: uma contribuição para as políticas de planejamento. Planejamento e Políticas Públicas, n. 41, p. 261-290, 2013.

SANTOS, J.; COSTA, J.; LEITE, F. Estrutura produtiva do Rio Grande do Norte: estimativas a partir de matrizes insumo-produto para os anos de 2010 e 2015. Revista Econômica do Nordeste, v. 51, n. 2, p. 117-136, 2020.

SCHUSCHNY, A. Tópicos sobre el modelo de insumo-producto: teoría y aplicaciones. Santiago: CEPAL, 2005.

SOUZA, I. Desindustrialização nos estados brasileiros: uma análise em painel para o período 1996-2014. 2016. 75 f. Dissertação (Mestrado em Economia) Universidade Federal de Uberlândia, Programa de Pós-Graduação em Economia, Uberlândia, 2016.

SZABÓ, N. Methods for regionalizing input-output tables. Regional Statistics, v. 5, n. 1, p. 44-65, 2015.

TEMURSHOEV, U.; MILLER, R.; BOUWMEESTER, M. A note on the GRAS method. Economic Systems Research, v. 25, n. 3, p. 361-367, 2013.

TEN RAA, T. The economics of input-output analysis. Nova Iorque: Cambridge University Press, 2005.

\section{Financiamento}

O presente trabalho foi realizado com apoio da Coordenação de Aperfeiçoamento de Pessoal de Nível Superior - Brasil (CAPES) - Código de Financiamento 001. 